\title{
Orobanche elatior and O. kochii (Orobanchaceae) in Poland: distribution, taxonomy, plant communities and seed micromorphology
}

\author{
Renata Piwowarczyk ${ }^{1 *}$, Łukasz Krajewski² \\ 1 Department of Botany, Institute of Biology, Jan Kochanowski University, Świętokrzyska 15, 25-406 Kielce, Poland \\ ${ }^{2}$ Department of Nature Protection and Rural Landscape, Institute of Technology and Life Sciences, Hrabska 3, Falenty, 05-090 Raszyn, Poland
}

\begin{abstract}
Species of the genus Orobanche (Orobanchaceae), parasitic on Centaurea in Central Europe, were previously considered to belong to the O. elatior group. At present, the taxon is differentiated into two species, O. elatior Sutton and O. kochii F.W. Schultz. The paper presents for the first time the distribution of O. elatior and O. kochii in Poland based on a critical revision of herbarium and the literature data, as well as the results of field studies conducted between 1999 and 2014. The majority of the species' localities are in south Poland: Silesia-Cracow, Małopolska and the Lublin Uplands. The distribution of both species in Poland is mapped and chronologically organized, and is thus the most recent in Europe. The taxonomy, host preferences, and ecology are also discussed. Seeds of both species were also investigated using light and scanning electron microscopy, which resulted in the designation of diagnostic features. The new color form of O. kochii f. citrina is described and illustrated. An account of all revised herbarium specimens collected from Poland, deposited in Poland and neighboring countries, is presented.
\end{abstract}

Keywords: Orobanche elatior; Orobanche kochii; taxonomy; distribution; phytocoenoses; SEM

\section{Introduction}

Orobanche and Phelipanche (syn. O. sect. Trionychon), are the largest genera in the Orobanchaceae family, and comprise more than 200 species, that lack chlorophyll and are root holoparasites of other vascular plants. Broomrapes are subcosmopolitan, with largest number of species being found in the warmer parts of the Mediterranean, Northern Africa, North America and Western and Central Asia. Several representatives, like $P$. ramosa, $P$. aegyptiaca, and O. crenata, parasitize important crops, e.g. tomatoes, tobacco, carrots [1-3]. In Europe they usually grow in the warmest regions, mostly in the Mediterranean countries. On the contrary, in central and northern parts of Europe the genera comprise about 30 species (17 established and 2 ephemerophytes from Poland), which are mostly rare, endangered or declining [e.g. 2,4-20]. These parasitic genera consist of plants, which possess very reduced vegetative organs and are highly variable. They are widely known for notorious difficulties in identifying, especially in herbarium material. For these reasons, there are a lot of erroneous determinations of species.

\footnotetext{
* Corresponding author. Email: renata.piwowarczyk@ujk.edu.pl
}

Handling Editor: Zygmunt Dajdok
Research into the species of the genus Orobanche parasitic on Centaurea scabiosa, previously considered as Orobanche elatior group, in Central Europe revealed the existence of two distinct and unrelated species. Their proper names proved to be O. kochii F.W. Schultz and O. elatior Sutton [21]. Centaurea scabiosa is the main host of $O$. kochii although single records have been reported on C. jacea, C. tenuifolia, C. triumfettii subsp. axillaris, C. stoebe, C. sadleriana, C. montana, and C. ruthenica; O. elatior is mainly parasitic on C. scabiosa and sporadically on C. jacea and C. tenuifolia $[9,13,21-23]$. It is interesting that two separate species parasitize the same host and some unrelated broomrapes have been found to parasitize the same host, e.g. Phelipanche bohemica (syn. $O$. bohemica), P. arenaria (syn. O. arenaria), O. coerulescens, or O. artemsiae-campestris on Artemsia campestris. Different species of the genus Artemisia are known as hosts of over 20 species of the genera Orobanche and Phelipanche [1].

Prior to studies conducted by Zázvorka [21], the name Orobanche elatior had been commonly used for over 100 years for an undifferentiated taxon of Eurasian distribution extending from Britain to China $[1,2,24,25]$. The distribution area of O. elatior (excluding O. kochii) is restricted to Western and Central Europe, also Nordic and Baltic countries. Orobanche elatior occurs mainly in England, the Netherlands, southern Sweden, southern Norway, Denmark, Switzerland, France, Italy and Germany, while eastwards its distribution 
area reaches the Baltic states, Poland, Slovakia, the Czech Republic, Slovenia, Romania [13,21,23] (also Piwowarczyk unpublished data, and http://www.nahuby.sk]. Its distribution eastwards is not yet known precisely. It is a rare species in the whole range.

Orobanche kochii is more common. It is Eurasian, continental species stretching from Central Europe to Central Asia, central China and India. Its distribution in Europe covers southeastern France, Italy, Austria, Hungary, the Czech Republic, Slovakia, Poland, Slovenia, Croatia, Serbia, Bosnia and Herzegovina, Romania, Bulgaria, Greece, Ukraine and European Russia. The species may occur in the Caucasus, Siberia, up to Central Asia and the Himalayas ([e.g. 13,21,23,26-30]). Distribution maps of O. kochii and O. elatior in Central Europe are included in the study by Zázvorka [21].

In Central Europe, the two species are primarily noted in xerothermic habitats, i.e. xerothermic grasslands of the class Festuco-Brometea and thermophilous fringes of the class Trifolio-Geranietea sanguinei, developed on limestone, marl, basalt, loess, at altitudes 200-750 m. Orobanche elatior is found in more semixerothermic and mesophilous communities mostly of the alliances Arrhenatherion and Bromion erecti, while $O$. kochii is encountered in more typical xeric steppe habitats [21]. The highest localities of O. elatior s.l. in Europe have been reported from the Swiss Alps at $1800 \mathrm{~m}$ and from Asia up to $2440 \mathrm{~m}[1,2]$.

The aim of this study was to identify the distribution of Orobanche elatior and O. kochii in Poland based on field investigations and verified herbarium and literature data. Prefered habitats, communities, hosts, taxonomic problems and threats to both species are also discussed. The new color form of $O$. kochii f. citrina is also described and illustrated. The objective of the present study is to investigate the micromorphology (SEM) of seeds of O. elatior, and O. kochii in order to establish if there are any micromorphologic characters diagnostic for the investigated taxa.

\section{Material and methods}

\section{Study area}

Field research was carried out in Poland in the xerothermic areas of the greatest concentrations of Orobanche s.l., i.e. in the Silesia-Cracow and Małopolska, and Lublin-Lviv, Volhynia Uplands, Polesie, Lower Oder and Vistula River, the Carpathian Mts and Carpathian Foothills, Sudetes Mts. The field investigations were conducted in 1999-2014, but mostly in 2006-2014. In parallel, the first author revised all the herbarium materials of $O$. elatior and $O$. kochii collected in Poland. The materials are deposited in Polish herbaria CHRZ, KRA, KRAM, KTC, KTU, LBL, LOD, POZ, WA, WRSL, the Czech Republic (PR), Hungary (BP), Germany (B, GLM), and in private herbaria. Herbarium acronyms are given after Mirek et al. [31] and Thiers [32].

\section{Relevé data}

The study is based on the analysis of phytosociological relevés with the occurrence $O$. elatior and $O$. kochii, according to Braun-Blanquet approach [33] and originating from
Poland. We performed more than 100 phytosociological relevés, but in this paper we presented the 39 (20 for O. elatior, 19 for $O$. kochii) most representative or significant. The nomenclature of vascular plants follows Mirek et al. [34]. The nomenclature of syntaxa is based on Matuszkiewicz [35].

\section{Data processing}

The localities of the both species are listed alphabetically as ATPOL cartogram units $(10 \times 10 \mathrm{~km})$ based on Zając [36]. Only localities recorded in our observations and identified or confirmed as well as verified herbarium data are listed. Published data not confirmed by us in the field or undocumented by herbarium materials are not reliable due to frequent determination errors and these incorrect/ doubtful localities are listed separately ("List of localities of Orobanche elatior and O. kochii in Poland" section below) and marked with a special symbol on the map.

Localities are described as follows: ATPOL grid unit, geographic location, habitat description, abundance in brackets. The following information is also given for most localities: geographic coordinates and altitude (above sea level), and for revised exsiccata the collector and collection date, exsiccatum number and the herbarium acronym. Archival maps of western Poland and military maps were used for localities reported in old data (http://mapy.amzp. pl/maps.shtml, http://www.mapywig.org/).

Symbols and abbreviations: app. - approximately, ATPOL - database, DG - Dąbrowa Górnicza, distr. - district, ecol. site - ecological site, exp. - exposure, gras. - grassland, leg. - collected by, n. - near, phot. - photography, res. - reserve, US - University of Silesia database, v. - valley, xer. gras. xerothermic grassland, vid. - seen by, ? - doubtful locality.

\section{Host analysis}

Host plants were observed by delicately exposing the soil with a gardening shovel. A total of 80 soil pits were observed in the field and in the analysis of herbarium materials containing an attached host.

\section{SEM analysis of seeds}

Seeds were extracted from 16 samples from 8 localities coming from Poland. The investigated material of $O$. elatior (4 localities: Baldram, Gipsowa Góra, Leszczany, Pińczów) and O. kochii (4 localities: Pęczelice, Wesołówka, Toporowice, Boria), has been collected in the field by the first author (see "List of localities of Orobanche elatior and O. kochii in Poland" section below); these specimens are deposited in KTC. Seeds were extracted from dried plants, mounted on stubs, coated with gold, and examined using a Joel JSM-7400F SEM, at various magnifications. Microscopic observations (LM) were carried out with a stereo microscope NIKON SMZ800 and a biological microscope NIKON Eclipse 50i.

Twelve characters (length, width, and outline of the seed and of the cells on their surface; height, width, and ornamentation of cell walls; presence of a median trough; form and diameter of seed wall perforation) were recorded. For each investigated taxon at least 30 seeds were examined. The terminology of seed surface is given after Barthlott [37,38], Stearn [39], Plaza et al. [40], Bojnansky and Fargasová [41], and Black et al. [42]. The collected data were subject 
to elementary statistical procedures [43], the mean, the standard deviation, and the lower and upper quartiles were calculated for each character of each of the three studied taxa. Statistical calculations were performed with Statistica 7.1.

\section{Results}

\section{Taxonomic notes}

Orobanche elatior Sutton

Orobanche elatior Sutton Transact. Linn. Soc. London 4: 178, 1798 [44]; Syn.: O. stigmatodes Wimmer Fl. Schles. 280, 1840 [45]; O. centaureae scabiosae Holandre Nouvelle Fl. Moselle, ed. 2, p. 520, 1842 [46]; O. confusa F.W. Schultz Fl. Pfalz 339, 1846 et Flora, Regensburg, 30: 66, 1847 [47], nom. inval., in syn. O. stigmatodes; O. major auct. non L. [48].

Lectotype (Foley 2001: 230): Norfolk, England, herb. Smith 1087.14 n. 1, LINN [49].

\section{Orobanche kochii F.W. Schultz}

Orobanche kochii F.W. Schultz Flora Regensburg, 30(5): 66, 1847 [47]; O. borbasiana Beck Bibl. Bot. (Monogr. Orobanche) 19: 173, 1890 [26]; O. elatior auct. (e.g. Beck in Halácsy et Braun, Nachträge zur Flora von NiederOesterreich, p. 128, 1882) [50], non Sutton; O. major auct. non L. [48]; O. major f. typica Beck, f. exigua Beck Bibl. Bot. (Monogr. Orobanche) 19: 170, 1890 et f. microphya Beck 1. c., p. 171 [26]; O. major f. moravica Beck Fedde Repert. 18: 36, 1922 [51]; O. major f. remotiflora Beck in Engler, Das Pflanzenreich (Monogr. Orobanchaceae) 96 (IV/261): 250, 1930 [27].

Lectotype: "Orobanche amethystea Thuill.? Auf mehreren Pflanzen des Gratzer Schlossberges, auch auf Anthericum ramosum !! - Blüht im Juli - August wenn an derselben Orten die O. rubens et O. galii ganz vertrocknet sind. 1840. Dr. Maly" (L, 0835152; cf. [21]).

The interesting history of O. elatior and O. kochii goes back to 1840 when Maly collected a specimen from Austria and included it into O. elatior Sutton [52] but later changed the identification to O. amethystea. Maly sent the specimen to Koch, who determined it as O. stigmatodes Wimmer in 1844. Koch forwarded the same material to Schultz, who described a new species, O. kochii F.W. Schultz, based on it in 1847 [47]. Schultz was the first to distinguish O. stigmatodes (=O. elatior) from $O$. kochii and also provided a key to their determination. Bohemian, Moravian and Silesian authors accepted this division and the two species were separated in subsequent studies (e.g. [53-55]).

Wimmer [45] described O. stigmatodes parasitic on C. scabiosa based on plants collected from Poland (Silesia) from the Góra Gipsowa hill in Dzierżysław near Kietrz. The species has occurred there until now [56]. The morphological description of $O$. stigmatodes and the herbarium material collected by Kelch (GLM, see list of localities) undoubtedly belongs to O. elatior Sutton s.str. Two species, O. elatior s.str. and O. caryophyllacea, have occurred on the Gipsowa Góra hill. A herbarium revision shows that the two species, especially O. elatior (e.g. $[26,27,54])$, have been mistaken with $O$. lutea and $O$. alsatica.
The confusion regarding the separation of $O$. kochii followed the publication of monographs by Beck [26,27], who included a non-homogenous group of taxa parasitic on Centaurea, Echinops or other Compositae, and even Ranunculaceae, into one species, O. major L. The division proposed by Beck was later followed by subsequent authors. Beck included eleven forms into O. major, five of which should have been included into O. kochii (after [21], see synonyms therein).

Some other forms of O. major distinguished by Beck were also later classified as separate species. They include f. krylowii (Beck) Beck, which was considered by Russian authors as a separate species, O. krylowii Beck, occurring in Russia and Central Asia. It is a parasite of the genus Thalictrum (Ranunculaceae) [28,29,57]. Surprising recent studies by Frajman et al. [58] reported O. krylowii in Albania, $2500 \mathrm{~km}$ of known localities. Based on morphological evidence, nuclear ribosomal ITS sequences, Frajman et al. have shown that the Albanian population belongs to O. krylowii and that its closest relative is the European O. lycoctoni, but not $O$. elatior as previously thought.

The form f. ritro (Grenier at Godron) Beck was considered as a separate species parasitic on Echinops, O. ritro Gren. \& Godr. [59] as early as in 1853. Some botanists treated O. ritro as a synonym for O. major or O. elatior (e.g. [60,61]). Zázvorka [21] includes it as a synonym of O. kochii. Recently, Pujadas-Salvà [62] reinstated its species rank as O. ritro, and has been adopted by other authors [20]. Carlón et al. [63] used O. loscosii to name the Iberian plants identified as $O$. ritro, however, Pujadas-Salvà [64] considers, that this species should be included among the synonyms for $O$. ritro.

Orobanche icterica Pau from the Iberian Penisula, traditionally synonymized with O. elatior Sutton, was recently reinstated for Spain by Pujadas-Salvà et al. [65] as a separate species, parasitizing C. aspera, C. fontanesii and Rhaponticoides linaresii, changing the earlier name O. leptantha Pomel [63]. Main differences were presented between $O$. ritro, O. elatior and O. icterica [62], and O. icterica and O. lepthanta [64]. Further research, including molecular analysis, may be interesting to explain relationship between O. elatior, O. ritro, O. kochii and Iberian species O. lepthantha and O. icterica. Moreover, recently has been discovered the locality of O. elatior from Lérida in Spain [63].

The form hypochoeridis (Druce ex Beck) Beck, described from the Chanel Islands, is at present classified in O. minor subsp. maritima var. hypochoeridis (Beck) Rumsey, parasitic on Hypochoeris radicata $[66,67]$.

Zázvorka [21] rightly renewed the division into O. elatior and $O$. kochii after nearly 100 years. During investigations into the genus Orobanche in Poland, the first author also noticed a lack of homogeneity of specimens considered as O. elatior. Lightly colored specimens with a dense inflorescence were initially treated as hypochromatic plants [68]. The above examples clearly show that many different taxa were placed in O. elatior and that this group of species requires further studies. A historical survey of Orobanche parasitizing Centaurea and the history and taxonomic contents of the related names are briefly discussed in a study by Zázvorka [21]. 


\section{The most important characters distinguishing \\ Orobanche elatior from 0 . kochii}

Both species are quite easily distinguishable when fresh. The corolla and stem in O. elatior are yellowish to ochre to light-brown or dirty-pale-pink (very rarely to dark-purple, rusty black, e.g. locality in Podskale) while O. kochii has a characteristic carrot-red to whitish-rosaceous or raspberry coloration (Fig. 1). Other characters are helpful in determining herbarium materials. Orobanche elatior is usually a large plant, with dense flowers; the corolla is regularly curved throughout, leaves are long and markedly narrow, linear-lanceolate. Orobanche kochii is mainly medium-sized; the corolla back is straighter in the middle, lower leaves on the stem are ovate to triangular, the spike subcylindrical and below lax. The two species also differ by the flowering period. Orobanche elatior flowers briefly and early, usually in late June, while $O$. kochii has a long flowering period, from late June until late August. A list of distinguishing characters is given in Tab. 1.

\section{A new form Orobanche kochii}

Orobanche kochii f. citrina R. Piwowarczyk \& Ł. Krajewski, f. nov. (Fig. 1).

Lemon-yellow forms of $O$. kochii are found in Boria and Jaworzno-Długoszyn. However, they are sometimes an extremely small part of a normally-colored population (Boria), or comprise $50 \%$ of the population (Jaworzno-Długoszyn). The yellow color of the stems in typically pigmented populations was observed during two summer seasons. This new taxon is very similar to typical $O$. kochii, and is compliant with morphometric characters in the description of the plant after Zázvorka [21], parasitizing C. scabiosa, but differs significantly by color; in typical $O$. kochii they are red or rosaceous, sometimes pale rosaceous-creamy, whereas in the form citrina whole plant are lemon-yellow with brownish leaves and bracts, drying out much earlier than the rest of the stem (Fig. 1). In addition, the citrina form individuals are slightly smaller - plants are shorter and sometimes have a shorter corolla. Interestingly, the creamy color corolla and stems are found in O. ritro, parasitizing Echinops, a taxon considered being a synonym of $O$. kochii [21] or a separate species by some authors [62] (see also "Taxonomic notes").

TYPE. Southern Poland, Boria (N of Ćmielów), xerothermic grassland on the slope of the Kamienna river valley, inclination SE, $50^{\circ} 58^{\prime} 15^{\prime \prime} \mathrm{N}, 21^{\circ} 32^{\prime} 53^{\prime \prime} \mathrm{E}$, alt. $167 \mathrm{~m}, 27$ June 2013, R. Piwowarczyk (holotype KTC!).

DESCRIPTION. Plants medium-sized, flowering stem simple, (5-)15-25(-40) cm high, lemon-yellow, glandularpubescent, glands whitish to pale yellow; dried specimens light-brown, cream-brown or cinnamon (do not always retain the lighter color after drying). Leaves broad at the base, ovate-triangular. Inflorescence (5-)12-15(-20) cm long, subcylindrical, tapering to the apex, usually 15-30-flowered. Bracts as long as the corolla or shorter. During florescence the bracts dry out quickly and are light-brown, particularly on their ends, which is very clearly seen in contrast to the lemon-yellow corolla and stem. Calyx segments are free or occasionally connate at base, $12-16 \mathrm{~mm}$ long, asymmetrically ovate and unequally bidentate. Corolla lemon-yellow (rarely whitish-yellow, whitish-lemon), (15-)20-28 mm long, dorsal line curved at the base, than nearly straight, glandular-pubescent, glands pale lemon-yellow or whitish. Stamens inserted 4-6 mm above the corolla base. Style sparsely glandular, stigma lobes deep yellow and usually darker than the corolla. Flowering period (late June) July to August. Parasitizing C. scabiosa (in Poland).

DISTRIBUTION AND ECOLOGY. Orobanche kochii f. citrina is currently known only from S Poland - Małopolska and the Silesia-Cracow Uplands (Boria and JaworznoDługoszyn). It is found in xerothermic grasslands of the Cirsio-Brachypodion pinnati alliance, on gentle slopes of hills, on soils rich in calcium carbonate, southern inclination, altitude 160-280 $\mathrm{m}$.

ETYMOLOGY. The form name originated from the lemon-yellow coloring of plants.

PARATYPES. Southern Poland, Jaworzno-Długoszyn E, hill with iron cross SE of church, secondary grassland Cirsio-Brachypodion pinnati, inclination SW, $50^{\circ} 14^{\prime} 43^{\prime \prime} \mathrm{N}$, $19^{\circ} 15^{\prime} 53^{\prime \prime}$ E, alt. 280 m, 4 August 2010, Ł. Krajewski (KTC!).

\section{Seeds micromorphology}

Orobanche elatior seeds are oblongoid, rare ovoid or subrectiangular, $(300-) 386(-450) \times(190-) 242(-320) \mu \mathrm{m}$. Epidermal seed coat cells are isodiametric to elongated; rare irregular and elongated, $(40-) 105(-160) \times(30-) 59(-100)$ $\mu \mathrm{m}$. Perforation diameter ranged (4-)7.9(-13) $\mu \mathrm{m}$, and its shape is elliptic to subcircular. The narrow trough is always present on the upper side of cell walls and is continuous. The wall width reaches (3-)6.1(-8) $\mu \mathrm{m}$ (Tab. 2, Fig. 2).

Orobanche kochii seeds are oblongoid, rare ovoid or subrectiangular, $(200-) 328(-410) \times(130-) 206(-300) \mu \mathrm{m}$. Epidermal seed coat cells are isodiametric to elongated; rare irregular and elongated, (55-)102(-170) × (35-)52(-90) $\mu \mathrm{m}$. Perforation diameter ranged (2-)2.7(-4) $\mu \mathrm{m}$, and its shape is subcircular. The narrow trough is always present on the upper side of cell walls and is continuous, sometimes with ornamentation. The wall width reaches (3-)4.2(-6) $\mu \mathrm{m}$, pitted, sometimes with additional and less ornamentation (Tab. 2, Fig. 2).

Preliminary results of micromophological examinations of seeds of $O$. kochii and O. elatior (then treated as two forms of $O$. elatior s.l.) have revealed differences in seed ornamentation, especially of the periclinal walls [68]. Our detailed studies demonstrated significant differences of diagnostic importance between O. elatior and O. kochii. The most important factor is the diameter and shape of the wall perforation. In O. elatior the perforation diameter is much larger, $4-13 \mu \mathrm{m}$, and is usually elliptical, while in $O$. kochii the diameter is smaller, $2-4 \mu \mathrm{m}$, and subcircular. Other characters of seed size and their cells are less important, but the analysis of a larger sample clearly demonstrated that seeds of O. elatior are larger than those of O. kochii (Tab. 2, Fig. 2).

\section{Determination problems and discriminating from other species}

Orobanche elatior belongs to a diversified section Orobanche (syn.: sect. /grex/ Curvatae Beck) [27], containing about 15 species. However, O. kochii probably has a relationship to another section Minores, this is supported by morphological characteristics, and preliminary molecular 

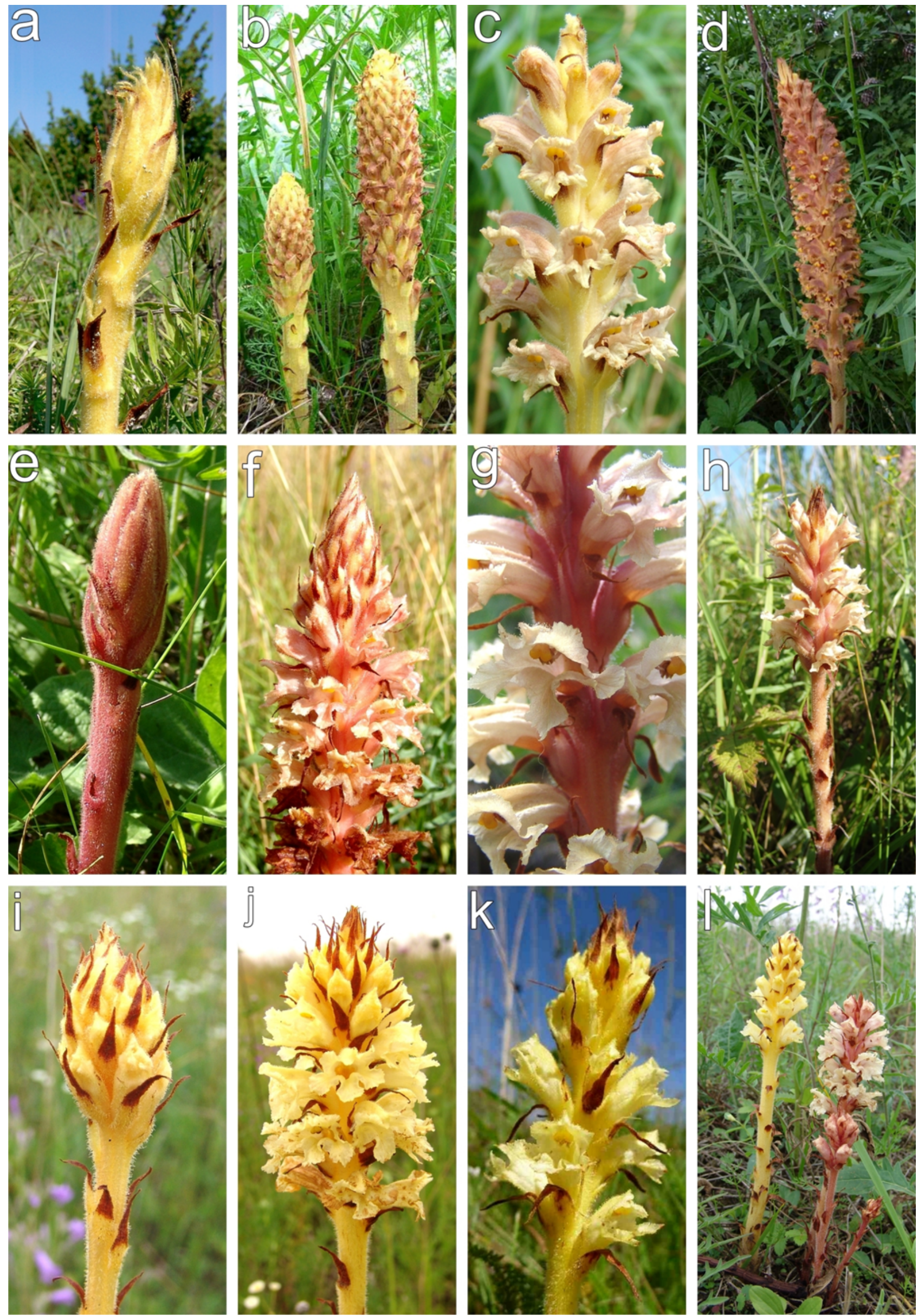
Fig. 1 General habit of the studied species. a-d Orobanche elatior. a Young bud, Turowiec, 03.06.2011, R. Piwowarczyk. b Young shoots, Dąbrowa Górnicza-Gołonóg, 10.06.2011, Ł. Krajewski. c Lax inflorescence, Baldram, 10.07.2010, R. Piwowarczyk. d Typical dense inflorescence, Dąbrowa Górnicza-Gołonóg, 10.06.2011, Ł. Krajewski. e-h O. kochii. e Young bud, Wesołówka, 30.06.2005, R. Piwowarczyk. f Inflorescence, Kaczkowice, 2008, R. Piwowarczyk. g Inflorescence, Wesołówka, 30.06.2005. h General habit of shoot, Gartatowice, 09.07.2013. i-1 O. kochii f. citrina. i Young bud. j Inflorescensce, 27.06.2013, Boria, R. Piwowarczyk. k Inflorescence, Jaworzno-Długoszyn, 05.08.2011, Ł. Krajewski. 1 General habit of shoot of O. kochii f. citrina, left and typical O. kochii, right, Boria, 27.06.2013, R. Piwowarczyk.

Tab. 1 The most important characters distinguishing Orobanche kochii and O. elatior [21] (corrected after our observations).

\begin{tabular}{lll}
\hline Characters & Orobanche kochii & Orobanche elatior \\
\hline Stem, height & Usually $(5) 20-30(60) \mathrm{cm}$ & Usually $(10) 30-40(95) \mathrm{cm}$ \\
Leaves, shape & Broad at base, ovate-triangular & Narrow, elongated, linear-lanceolate \\
Inflorescence & Subcylindrical (tapering to the apex) and below lax & Cylindrical and dense (often with an additional, \\
& & narrow, acute top of unopened flower buds) \\
Corolla and stem, color (in fresh & Carrot red to whitish-rosaceous, raspberry; & Deep yellow to pale brown (ochre), pale rosaceous, \\
materials) & Rarely also entire plants lemon-yellow; stem usually & very rare to dark purple violet (almost black); stem and \\
& with stronger coloration, corollas lighter & corolla in the same color \\
Back of corolla & The middle of the back nearly straight & Regularly curved throughout \\
Dried specimens & Brownish-rusty, cinnamony, darker & Pale brown (ochre), paler \\
Flowering period & Lengthy, (late June) July-August (September) & Very short (only 2 weeks), mid-June \\
Host (Central Europe) & Centaurea scabiosa, occasionally C. stoebe & Centaurea scabiosa
\end{tabular}

Tab. 2 A comparison of the main characters distinguishing seeds of Orobanche elatior and O. kochii.

\begin{tabular}{lll}
\hline Characters & Orobanche elatior & Orobanche kochii \\
\hline Seed length $(\mu \mathrm{m})$ & $(300-) 386(-450)$ & $(200-) 328(-410)$ \\
Seed width $(\mu \mathrm{m})$ & $(190-) 242(-320)$ & $(130-) 206(-300)$ \\
Cell length $(\mu \mathrm{m})$ & $(40-) 105(-160)$ & $(55-) 102(-170)$ \\
Cell width $(\mu \mathrm{m})$ & $(30-) 59(-100)$ & $(35-) 52(-90)$ \\
Perforation diameter $(\mu \mathrm{m})$ & $(4-) 7.9(-13)$ & $(2-) 2.7(-4)$ \\
Wall width $(\mu \mathrm{m})$ & $(3-) 6.1(-8)$ & $(3-) 4.2(-6)$ \\
Seed shape & Oblongoid, rare ovoid or subrectiangular & Oblongoid, rare ovoid or subrectiangular \\
Cell shape & Isodiametric to elongated; rare irregular & Isodiametric to elongated; rare irregular \\
Perforation shape & Elliptic, rarely subcircular & Subcircular \\
Wall depth & Medium & Medium \\
Wall ornamentation & Pitted or slightly pitted & Pitted, sometimes with additional and less \\
& & ornamentation \\
Narrow trough & Evident around cells & Evident around cells, sometimes with \\
& & ornamentation \\
\hline
\end{tabular}

evidence (Piwowarczyk et al. unpublished); it was also initially indicated in the work of Carlón et al. [63].

Typical O. kochii is clearly distinguished from O. elatior and they are easily differentiated. Orobanche kochii is a distinctive species and it does not have any morphologically similar taxa in Central Europe. However, O. elatior in Central Europe is similar in morphology to O. alsatica and $O$. bartlingii. Some specimens in herbarium materials lacking information on the host are difficult to diagnose. It is crucial to note the host of plants of the genus Orobanche, especially for O. elatior. Orobanche elatior is parasitic on Centaurea (mainly C. scabiosa), O. alsatica on Peucedanum 

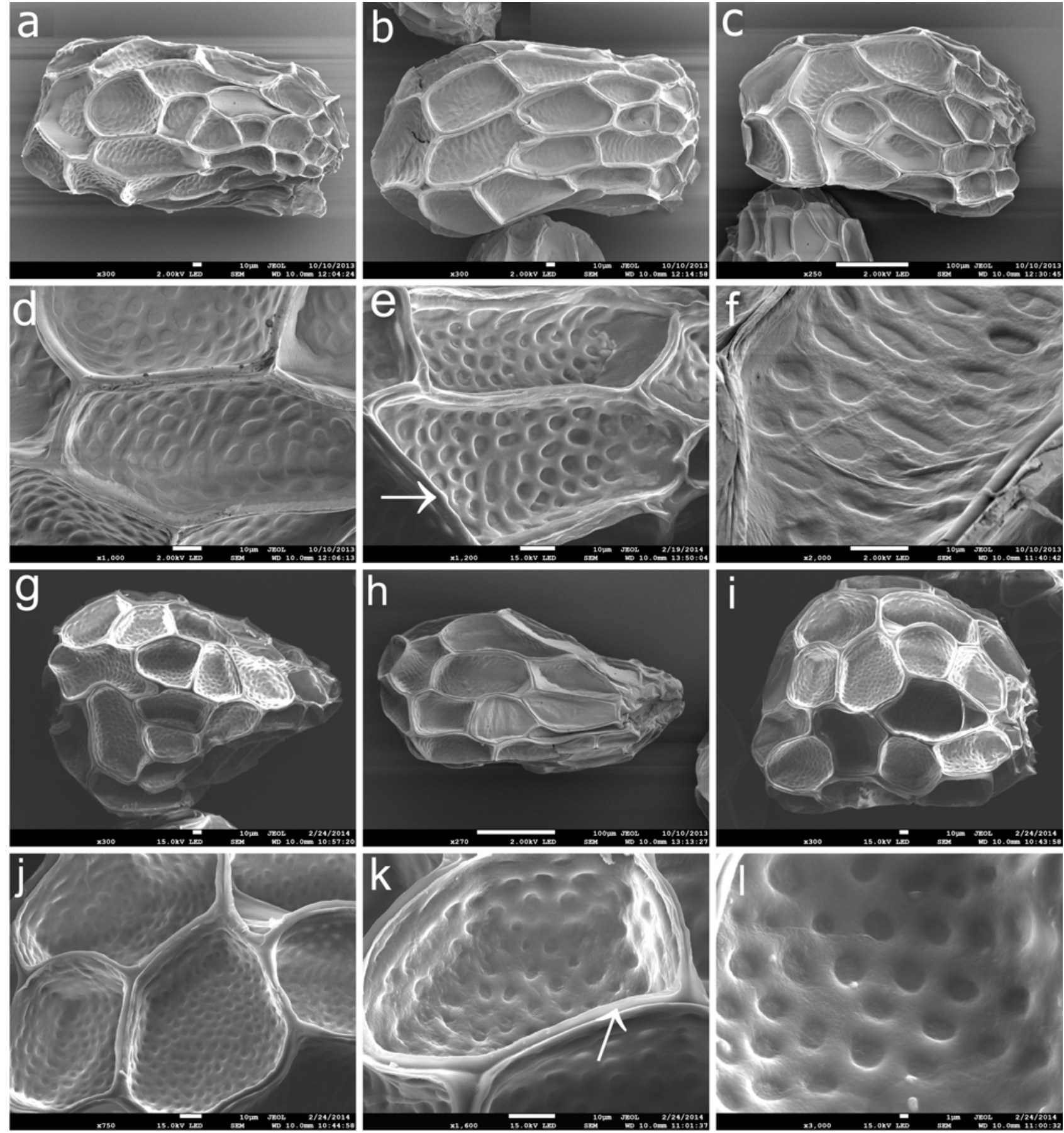

Fig. 2 Micromorphology of seeds of the studied species in SEM micrographs (surfaces). a-f Orobanche elatior. g-l O. kochii. a-c,g-i general habit of seeds; $\mathbf{d}-\mathbf{f}, \mathbf{j}-\mathbf{l}$ - variation of sculpture, perforation diameter and their shape; arrows indicate the narrow trough.

(chiefly P. cervaria, sporadically P. alsaticum), rarely on Seseli osseum and S. austriacum, while O. bartlingii on Libanotis pyrenaica. Even results of molecular studies have revealed close relationships between O. elatior and O. alsatica [69]. It seems that these relationships will be especially close between $O$. bartlingii and O. flava. Incorrect determinations can also be related to O. elatior and O. flava. However, O. flava is evidently distinguished from other taxa by different phytoceonoses, usually mountain hydric scrub on streams, and by parasitism on the genus Petasites. Lack of information regarding the host can also cause determination problems.
Monstrous shoots of $O$. elatior, branched into 2-4 inflorescences, with a tape-like stem, multiflorous inflorescence, with incorrectly placed flowers, are encountered occasionally (rarely), e.g. Leszczany in the Lublin region and DG-Błędów in the Dąbrowa Basin. This is probably related to herbicide on farmland near localities.

\section{Distribution in Poland}

The revision of and detailed field investigations into O. elatior and O. kochii in Poland have revealed considerable differences in the distribution, especially in relation 
to the previous distribution map of O. elatior s.l. [70]. The study also significantly changed and updated the previous distribution map for both species in central Europe prepared by Zázvorka [21].

At present O. elatior in Poland mainly occurs in the Silesia-Cracow, Małopolska and Lublin Uplands, rarely in the Lower Vistula Valley, Central Sudetes Mts and the Carpathian Foothills. Orobanche kochii, which is more common than O. elatior, has numerous localities but almost exclusively in the Polish uplands in a very compact range (Fig. 3, Fig. 4).

Only data verified in the field or confirmed by the herbarium material or photographic documentation is listed below. Due to frequent incorrect determinations, localities reported in the literature and unpublished localities that are not documented by herbarium material and not verified by us in the field are listed separately and marked with a special symbol on the map. Localities in the maps have been differentiated into three time periods, in order to illustrate the most current and the actual state distribution of both species (Fig. 3, Fig. 4).

Many literature reports may not be reliable due to the host they provide, e.g. Medicago falcata, where O. elatior s.l. was probably mistaken with O. lutea and others (e.g. [71-77]). Corrections are also needed for photographs of $O$. kochii [68,78-80] or O. lutea [81], captioned as O. elatior.

\section{List of localities of Orobanche elatior and 0 . kochii in Poland}

Orobanche elatior

AC: 30 - Bielinek, leg. R. Schulz 1914, 1925 (B) [82-85]; E of Bielinek, on a grassy SW slope of the Oder v.; leg. J. Mądalski, 21.09.1955 (KRAM, 494779); leg. Exc. Inst. Bot. U. P., 06.1952 (POZ); BF: 24 - Słoszów, xer. gras. of the alliance Bromion erecti on the margin of an old limestone quarry W of Słoszów, (<10), 630 m [86]; Raczyn, overgrowing gras. on the forest margin, Bromion erecti, $(<100), 700 \mathrm{~m}$ [86]; Zielone, thermophilous gras. of the alliance Bromion erecti (a few hundred specimens), 680-700 m [87-89]; between Zielone and Słoszów, a belt of dry gras. on the forest margin, (8), 650 m [86,87]; 36 - Śnieżnik Massif, Krowiarki, $0.3 \mathrm{~km} \mathrm{NW}$ of the summit Kamiennik, SW slope xer. gras. of the alliance Bromion erecti, a narrow strip between the cultivated field and spruce forest, (7), 50 $10^{\prime} 46^{\prime \prime} \mathrm{N}, 16^{\circ} 43^{\prime} 38^{\prime \prime} \mathrm{E}$, 560 m, vid. M. Karakula, det. M. Smoczyk, 17.06.2014 (phot.); $0.3 \mathrm{~km}$ to the NW and SE from the top of the mountain Kamiennik, xer. gras. of the Bromion erecti and Trifolion medii aliances, (7), 550-560 m, vid. M. Karakula, M. Smoczyk, 01.07 .2014 (phot.); CE: 00 - Kaszowo, Milice distr., thermophilous meadow, NW exp. (40), vid. L. Matacz, 23.06.2014 (phot.), CF: 46 - between Borzysławice and Karchów (Borislawitz u. Karchwitz) [54,55,90]; Silesia, Kędzierzyn-Koźle distr., Pawłowiczki; Borzysławice village, small forest in the direction of Karchów (Borislawitz im Waldchen gegen Karchwitz), leg. R. Uechtritz, 07.1867 (PR); 65 - Gipsowa Góra res., Dzierżysław n. Kietrz, Góra Gipsowa hill n. Kietrz, leg. Kelch, 18?? (GLM, 138802), leg.?, 18?? (GLM, 138799); leg. Wetschky, 06.1872 (WA, 30508); Silesia, distr. Głubczyce, Kietrz village, Góra Gipsowa nature res. [21,27,45,54-56,91]; xer. gras., leg. A. Sendek, 14.05 .1972 (KRA, 0138561, 01385670); leg. J.J. Wójcicki, 29.06.1973 (KRAM, 405945); leg.?, 17.07.1964 (KRAM, 356938); sunny slope, leg. E. Kozioł, 15.06.1983, 15.06.1985 (WRSL, 93091, 93092, 93093); leg. M. Buchalik, 26.06.1999 (KTU, 99023); leg. A. Sendek, 14.06.1972 (KTU, 01055); meadow below the reserve, leg. K. Rostański, 04.07.1978 (KTU, 29273), $50^{\circ} 03^{\prime} 21.04^{\prime \prime} \mathrm{N}, 17^{\circ} 59^{\prime} 33.3^{\prime \prime}$ E, 262 m, leg. R. Piwowarczyk 11.07.2010; 68 - Kozłówki (Kösling) [54]; Czernica (Czernitz zwischen Rybnik und Ratibor) [54,55]; DB: 52 - Baldram,

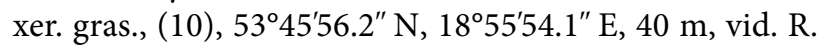
Piwowarczyk, 10.07.2010; DE: 11 - cfr., Burzenin, Sieradz distr., alfa alfa cultivation, leg. A. Janković, 28.07.1967 (LOD, 154399); DF: 22 - between Orzech and Radzionków, W of railway, field baulk with Solidago and termophilous scrubs,

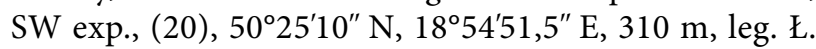
Krajewski, 29.07.2011, (Bitoft 1979, US); 24 - Podskale NW, hill 317, gras. on field baulk, SE exp., (very rare, mixed with O. lutea), $50^{\circ} 25^{\prime} 20^{\prime \prime} \mathrm{N}, 19^{\circ} 13^{\prime} 09^{\prime \prime} \mathrm{E}, 310 \mathrm{~m}$, leg. . Krajewski, 27.06.2010 (KTC), vid. Ł. Krajewski 2009-2011, 2013; DGUjejsce E, W of the Recki Las forest, dry, sandy old fallow, overgrowing Pinus and Calamagrostis, NE exp., (40, 150, 30), $50^{\circ} 24^{\prime} 04^{\prime \prime} \mathrm{N}, 19^{\circ} 16^{\prime} 04^{\prime \prime} \mathrm{E}, 335 \mathrm{~m}$, leg. Ł. Krajewski, 05.08.2010 (KTC), vid. Ł. Krajewski 2010-2011, 2013; DGGołonóg, Mała Góra Gołonoska (hill 334), xer. gras., overgrowing Crataegus and Solidago, SW, S exp., (25, 50, 20, 15, 10,15 , in upper part of site close to O. kochii and from 2011 also O. lutea), $50^{\circ} 20^{\prime} 05^{\prime \prime} \mathrm{N}, 19^{\circ} 14^{\prime} 22^{\prime \prime} \mathrm{E}, 324-332 \mathrm{~m}$, vid. $€$. Krajewski 2009-2014, phot.; 26 - between Grabowa and Kromołowiec rocks, rendzina fallow in field roadside, under power line, $\mathrm{N}$ exp., (very rare), 50 $23^{\prime} 50^{\prime \prime} \mathrm{N}, 19^{\circ} 26^{\prime} 58^{\prime \prime} \mathrm{E}$, 415 m, leg. Ł. Krajewski, 02.10.2009 (KTC); cfr., Grabowa E, SE slopes of Wierzgóry (hill 423), above road to Piaski, old fallows, (very rare), $50^{\circ} 23^{\prime} 15^{\prime \prime} \mathrm{N}, 1^{\circ} 28^{\prime} 32^{\prime \prime} \mathrm{E}, 345 \mathrm{~m}$, leg. Ł. Krajewski, 18.09.2009 (KTC), later not found; 35 - DGŁęka NW, hill 361 (Łosy), calcareous gras. with Thalictrum simplex, strongly overgrowing Prunus spinosa and Crataegus monogyna, thermophilous scrubs, field margins, (30, 25, 3, 50, 20; from 2011 with O. lutea, O. kochii also occurred in 2013), $50^{\circ} 22^{\prime} 11^{\prime \prime} \mathrm{N}, 1^{\circ} 20^{\prime} 02^{\prime \prime} \mathrm{E}, 360 \mathrm{~m}$, leg. E. Krajewski, 27.09.2009 (KTC), vid. Ł. Krajewski 2008-2011, 2013; Sławków, NE Tomanówka (hill 350, Góra Wielka massif), ecotone of fallows and calcareous/calamine gras. with Libanotis, overgrowing Solidago and Calamagrostis, NW, N, NE exp., (25, 50, 30; mixed with O. lutea in upper part, only in 2009 also present $O$. picridis), $50^{\circ} 19^{\prime} 29^{\prime \prime} \mathrm{N}, 19^{\circ} 21^{\prime} 17^{\prime \prime} \mathrm{E}$, $50^{\circ} 19^{\prime} 28^{\prime \prime} \mathrm{N}, 1^{\circ} 21^{\prime} 14^{\prime \prime} \mathrm{E}, 335-340$ m, leg. Ł. Krajewski, 09.08.2009, 10.08.2009 (KTC), vid. Ł. Krajewski 2009-2011, 2013; Sławków-Kozioł N, Geranion sanguinei with dominant Libanotis, (very rare, with O. lutea, close to O. picridis), $50^{\circ} 18^{\prime} 41^{\prime \prime} \mathrm{N}, 19^{\circ} 21^{\prime} 57^{\prime \prime} \mathrm{E}, 332 \mathrm{~m}$, leg. Ł. Krajewski, 09.07.2011 (KTC); Sławków N, 650 m NNE of hill 345, S of field road, calcareous rocky gras./thermophilous scrubs, NE exp., (very rare, mixed with $O$. lutea and $O$. bartlingii), 50 $19^{\prime} 06,3^{\prime \prime} \mathrm{N}$, $19^{\circ} 23^{\prime} 05,4^{\prime \prime}$ E, 310 m, leg. Ł. Krajewski, 23.07.2010 (KTC), vid. Ł. Krajewski 2010-2011, 2013; 36 - DG-Błędów, hill $341 \mathrm{~m}$ (Młyńska Mt or Kamieniec; entire ridge $1.5 \mathrm{~km}$ long), old fallow rendzinas, margins of ploughed fields, baulks, thermophilous scrubs, small limestone quarries, calcareous grasslands, meadows, N, NW, W, SE exp., (150), 50²1'13" N, $19^{\circ} 27^{\prime} 01^{\prime \prime} \mathrm{E}, 50^{\circ} 21^{\prime} 12^{\prime \prime} \mathrm{N}, 1^{\circ} 26^{\prime} 54^{\prime \prime} \mathrm{E}, 50^{\circ} 20^{\prime} 54,9^{\prime \prime} \mathrm{N}$, $19^{\circ} 27^{\prime} 46,3^{\prime \prime} \mathrm{E}, 50^{\circ} 20^{\prime} 57^{\prime \prime} \mathrm{N}, 19^{\circ} 27^{\prime} 51^{\prime \prime} \mathrm{E}$ (only here mixed with O. kochii in lower part), $50^{\circ} 20^{\prime} 53^{\prime \prime} \mathrm{N}, 19^{\circ} 28^{\prime} 09^{\prime \prime} \mathrm{E}, 320-335$ 


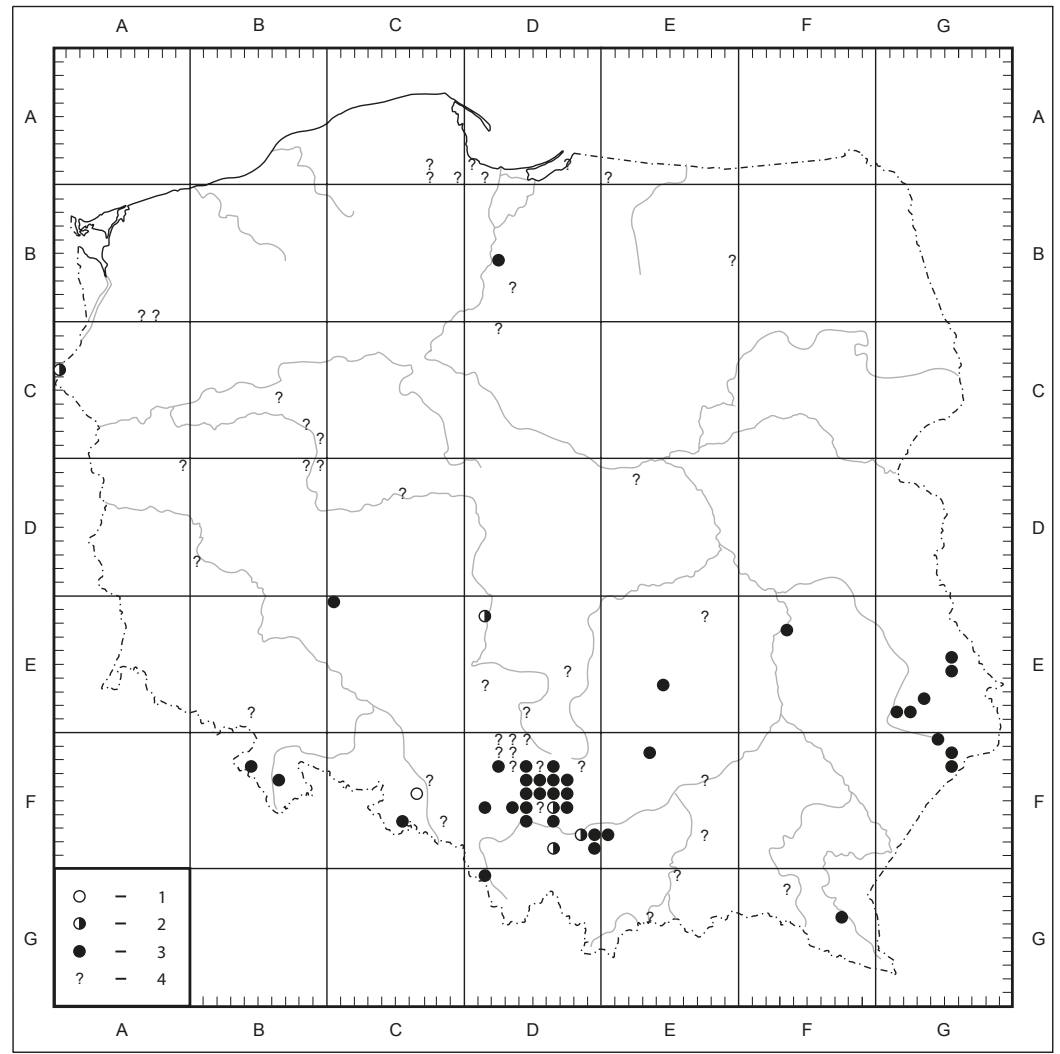

Fig. 3 Distribution of Orobanche elatior in Poland: 1 - before 1950, 2 - 1950-2000, 3 - after 2000, 4 - only literature data of O. elatior s.l., uncertain.

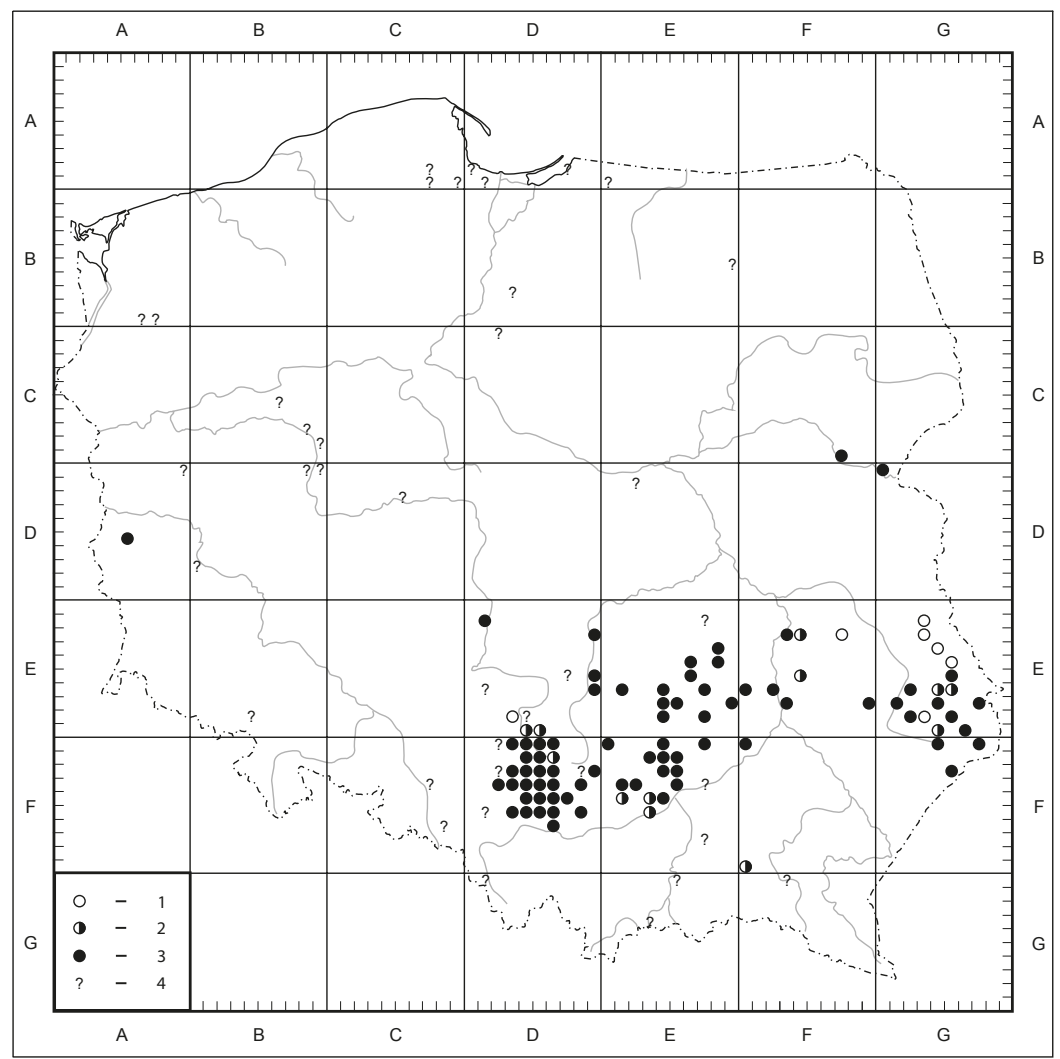

Fig. 4 Distribution of Orobanche kochii in Poland: 1 - before 1950, 2 - 1950-2000, 3 - after 2000, 4 - only literature data of O. elatior s.l., uncertain. 
m, leg. Ł. Krajewski, 25.09.2009, 26.09.2009, 10.07.2011 (KTC, also monstrous shoots - stem forked to 2, 4 inflorescences and flat), vid. Ł. Krajewski 2009-2014; ChechłoPustkowie, Buczna Góra hill, roadside, NW exp., (very rare,

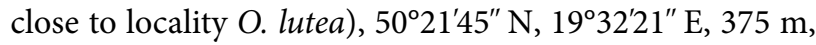
leg. Ł. Krajewski, 26.09.2009 (KTC); 37 - Kolbark, near Wilcze Doły, xer. gras., fallows, baulks, $(>5), 50^{\circ} 21^{\prime} 38,5^{\prime \prime} \mathrm{N}$, $19^{\circ} 39^{\prime} 28,9^{\prime \prime} \mathrm{E}, 407 \mathrm{~m}, 50^{\circ} 21^{\prime} 34,5^{\prime \prime} \mathrm{N}, 19^{\circ} 39^{\prime} 33,1^{\prime \prime} \mathrm{E}, 379 \mathrm{~m}$, vid. R. Piwowarczyk, 31.09.2011; Cieślin N, Organistówka hill, S slopes $100 \mathrm{~m} \mathrm{E}$ of church, old rendzina fallow with xer. gras., $(15,25), 50^{\circ} 22^{\prime} 17^{\prime \prime} \mathrm{N}, 1^{\circ} 37^{\prime} 35^{\prime \prime} \mathrm{E}, 345 \mathrm{~m}$, leg. . Krajewski 10.09.2013, vid. Ł. Krajewski, 13.06.2014; Domaniewice S, $50 \mathrm{~m} \mathrm{~S}$ of road Bydlin-Wolbrom, balk of field road, fallow with xer. gras., (10), 50²2'51" N, 19²40'19" E, 375 m, vid. Ł. Krajewski 13.06.2014; 44 - Jaworzno-Niedzieliska, Warpie NW (Wał hill), N of allotments, ThalictroSalvietum pratensis evolving to Prunetalia spinosae, E exp., $\left(35,25\right.$; mixed with less numerous $O$. lutea), $50^{\circ} 24^{\prime} 04^{\prime \prime} \mathrm{N}$, $19^{\circ} 16^{\prime} 04^{\prime \prime}$ E, 310 m, leg. Ł. Krajewski, 04.08.2010 (KTC), vid. Ł. Krajewski, 12.06.2011; 45 - Jaworzno-Ciężkowice SW, Góra Wielkanoc Mt (hill 331), calcareous gras., S, SW exp., $(10,20$; mixed with O. lutea, O. kochii $100 \mathrm{~m} \mathrm{~W}), 50^{\circ} 12^{\prime} 39^{\prime \prime} \mathrm{N}$, $19^{\circ} 20^{\prime} 40^{\prime \prime}$ E, 327 m, leg. Ł. Krajewski, 08.08.2010 (KTC), vid. Ł. Krajewski 2010-2011; 46 - Żurada, S of Kolonia I, NE slopes of hill 439, calcareous gras. and scrubs, fallows, field baulks, $\mathrm{N}$ exp., (50), 50¹4'58" N, 19³2'22" E, 425-430 m, leg. Ł. Krajewski, 13.09.2011 (KTC); 47 - Olkusz NE, hill 423 , S slope, baulk between field road and new house, calcareous gras. (20), $50^{\circ} 17^{\prime} 10^{\prime \prime} \mathrm{N}, 1^{\circ} 34^{\prime} 44^{\prime \prime} \mathrm{E}, 415-420 \mathrm{~m}$, leg. Ł. Krajewski, 15.09.2011 (KTC); Kosmolów N, S of Podłużne forest, close to Eagles' Nests red trail, NE slopes of hill 438, dry, sandy meadow, xer. gras. on fallow rendzinas, roadsides, NE, $\mathrm{N}$ exp., (60; $500 \mathrm{~m}$ E of $O$. kochii's site), $50^{\circ} 16^{\prime} 48^{\prime \prime} \mathrm{N}$, $19^{\circ} 39^{\prime} 29^{\prime \prime} \mathrm{E}, 50^{\circ} 16^{\prime} 52,5^{\prime \prime} \mathrm{N}, 1^{\circ} 39^{\prime} 23^{\prime \prime} \mathrm{E}, 50^{\circ} 16^{\prime} 54^{\prime \prime} \mathrm{N}$, 19³9'29" E, 400-420 m, leg. J. Drobnik, 06.07.2001 (KTU, 99021), leg. Ł. Krajewski, 10.07.2011 (KTC) [92]; 51 Mikołów-Mokre, Fiołkowa Góra hill, (Nikolai: Mokrauer Kalkberg) [93]; dry meadow on N slope, leg. M. Dobrzańska, 28.08.1977 (KTU, 16211); leg. M. Klączek, 01.08.1983 (KTU, 38299) (Babczyńska-Sendek 1998, Urbisz 2001, US); Mikołów, Sośnia Góra (hill 329), gras. areas of the botanical garden, (10), vid. W. Podstolski 06.2013, phot.; 53 - Lędziny SW, Góra Klimont Mt (hill 302), SW of St. Clement church, xer. gras., (very rare, mixed with $O$. kochii), $50^{\circ} 07^{\prime} 13^{\prime \prime} \mathrm{N}$, $19^{\circ} 06^{\prime} 08^{\prime \prime}$ E, 295 m, leg. Ł. Krajewski, 13.09.2010 (KTC); 54 - between Imielin-Pasieczki and Mysłowice-Dziećkowice, hill 310, calcareous xer. gras., S exp., $(15,250 \mathrm{~m}$ to $\mathrm{W}$ of $O$.

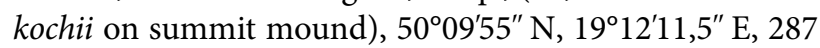
m, leg. Ł. Krajewski, 04.09.2010 (KTC); 56 - between Dulowa and Młoszowa, n. Trzebinia, calcareous slope close to road, leg. A. \& J. Kornasiowie, 08.08.1955 (KRAM, 014846); 57 - between Wola Filipowska and Krzeszowice, xer. gras. on the border of hamlets Pasternik and Podgórki, on a hillside Skałka, (32), 5007.230'N, 19³5.893'E, 305 m, leg. B. Binkiewicz, 08.07.2014 (KTC); 64 - Chełm Śląski E, Smutna Góra Mt (hill 285 with cholera cemetery), xer. gras., old limestone quarries, (20), $50^{\circ} 06^{\prime} 30^{\prime \prime} \mathrm{N}, 19^{\circ} 12^{\prime} 44^{\prime \prime} \mathrm{E}, 50^{\circ} 06^{\prime} 26^{\prime \prime} \mathrm{N}$, $19^{\circ} 12^{\prime} 50^{\prime \prime}$ E, 275-280 m, leg. Ł. Krajewski, 04.09.2010 (KTC), vid. P. Grzegorzek, 07.2014 (phot.); 66 - between Wygiełzów and Zagórze, pass between Grodzisko Wielkie and Małe hills, in C. scabiosa population, very abundant, leg. P. Grzegorzek, 10.07.1989 (Grzegorzek private herbarium); 79 Ochojno Świątniki Górne distr., n. Stronie estate, overgrowing Festuco-Brometea gras. with C. scabiosa, on a small hill $n$. houses in the estate, W exp., (Pogórze Wielickie, Western Carpathian Mts), (>40), leg. W. Bartoszek, 15.06.2002 (KRA, 0260657, 0260658, 0260579, 0260586); 78 - cfr., between Rzozów and Radziszów n. Skawina, NW slope of Lipie hill, leg. H. Trzcińska-Tacik, 1980 (KRA); 86 - Wadowice, between road bridge and railway bridge, leg. E. Markiewicz, 19.06.1992 (KTU, 45891); 89 - Siepraw (Sieprawski), S slope, gras., leg. K. Hajduk, 20.09.2009 (KRA); DG: 01 - Tuł, calcareous hill between Goleszów and Leszna (Śląsk Cieszyński), leg. A. Żmuda, (KRAM, 061500); In Getriedefeldern am Tuł bei Ustroń (Schlesien), leg. F. Pax, 06.1888 (BP); Tuł bei Teschen, leg. Fiek, 16.07.1858 (WA, 30506), leg. Fiek, 18.07.1888 (BP), (Silesia, Cieszyn distr., Tuł hill SW of Ustroń town); Tuł [21,54,55,94-97]; vid. M. Śniegoń, 06.2000 (phot.), vid. T. Beczała, 2003 (has not occurred since 2008); EE: 64 - Zachełmie n. Zagnańsk, xer. gras. on the edges of a closed quarry $n$. Chełmowa hill $(<10)$, $50^{\circ} 58^{\prime} 10^{\prime \prime} \mathrm{N}, 20^{\circ} 41^{\prime} 28^{\prime \prime} \mathrm{E}, 354 \mathrm{~m}$, vid. A. Przemyski, 09.2011 (phot.) [13]; EF: 13 - Góry Pińczowskie Mts, NW of Pińczów, margin of a field and a fallow (3), 50 $32^{\prime} 08,4^{\prime \prime} \mathrm{N}, 20^{\circ} 30^{\prime} 46^{\prime \prime} \mathrm{E}$, 219 m , leg. R. Piwowarczyk, 09.06.2009 (KTC) [13,14]; Polana Polichno res. n. Młodzawy, xer. gras., oak-hornbeam communities (>8), 50²8'01,9" N, 20²8'06,7" E, $215 \mathrm{~m}$, leg. R. Piwowarczyk, 27.06.2006, (KTC), vid. R. Piwowarczyk, 06.2009 [13]; 70 - Koźmice Wielkie n. Wieliczka, dry gras. Festuco-Brometea, at the foot of a mound (Pogórze Wielickie, Western Carpathian Mts), leg. W. Bartoszek, 12.06.2002 (KRA, 0260473, 0260474, 0260484, 0260583, 0260584, 0260585, 0260590) [79]; EG: 05 - cfr., Znamirowice on lake Rożnowskie, W slope of Grochówki [98]; FG: 37 - Myczkowce n. Olszanica, slope on the San river, vid. M. Szewczyk (phot.), 07.06.2012; GE: 45 - Wólka Leszczańska, a narrow belt of xer. gras. between the "Żmudz" res. and the village (>5), 51 ${ }^{\circ} 00^{\prime} 41^{\prime \prime} \mathrm{N}, 23^{\circ} 39^{\prime} 09^{\prime \prime} \mathrm{E}$, leg. P. Chmielewski, R. Piwowarczyk, 08.06.2008 (KTC) [9]; Leszczany, a fallow field and an arable field adjacent to a former limestone excavation pit, by the Żmudź-Kumów Majoracki road, near village buildings $(<50)$. Some specimens were deformed, probably following treatment with weed killers. $51^{\circ} 01^{\prime} 29^{\prime \prime} \mathrm{N}$, $23^{\circ} 34^{\prime} 53^{\prime \prime}$ E, leg. P. Chmielewski, R. Piwowarczyk, 09.06.2007 (KTC) [9]; 55 - Żmudź, xer. gras. and scrub in the "Żmudź" reserve and along its borders, ca. $0.5 \mathrm{~km}$ W of Kolonia Żmudź (>10), 51 ${ }^{\circ} 00^{\prime} 29^{\prime \prime} \mathrm{N}, 23^{\circ} 40^{\prime} 27^{\prime \prime} \mathrm{E}$, leg. R. Piwowarczyk, P. Chmielewski, 08.06.2007 (KTC) [9]; Podlesie, a xer. gras. and blackthorn scrub, ca. $1 \mathrm{~km} \mathrm{~S}$ of Wólka Leszczańska (>20), 51 $01^{\circ} 03^{\prime \prime} \mathrm{N}, 23^{\circ} 39^{\prime} 03^{\prime \prime}$ E, vid. P. Chmielewski, 2007 [9]; Turowiec, a vast complex of initial xer. gras. and juniper scrub, ca. $1.5 \mathrm{~km} \mathrm{~N}$ of the cemetery near Turowiec and

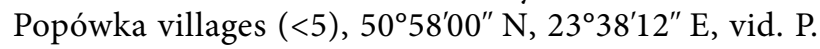
Chmielewski 2007, xer. gras. with Juniperus communis, (2), 5057 59,5N, 2338 11,9E, vid. R. Piwowarczyk 03.06.2011 [9]; 55/56 - Kolonia Teresin, roadsides, fallow fields, xer. gras. and sparse blackthorn scrub on a vast calcareous scrub ca. $0.5 \mathrm{~km} \mathrm{~S}$ of the village (>30), 50 $59^{\prime} 41^{\prime \prime} \mathrm{N}, 23^{\circ} 40^{\prime} 54^{\prime \prime} \mathrm{E}$; $50^{\circ} 58^{\prime} 43^{\prime \prime} \mathrm{N}, 23^{\circ} 41^{\prime} 57^{\prime \prime} \mathrm{E} ; 50^{\circ} 59^{\prime} 19^{\prime \prime} \mathrm{N}, 23^{\circ} 41^{\prime} 29^{\prime \prime} \mathrm{E} ; 50^{\circ} 58^{\prime} 49^{\prime \prime} \mathrm{N}$, $23^{\circ} 42^{\prime} 09^{\prime \prime} \mathrm{E} ; 50^{\circ} 59^{\prime} 01^{\prime \prime} \mathrm{N}, 23^{\circ} 41^{\prime} 11^{\prime \prime} \mathrm{E}$; $50^{\circ} 58^{\prime} 46^{\prime \prime} \mathrm{N}, 23^{\circ} 41^{\prime} 25^{\circ} \mathrm{E}$; 
$50^{\circ} 59^{\prime} 20^{\prime \prime} \mathrm{N}, 23^{\circ} 42^{\prime} 00^{\prime \prime}$ E, leg. P. Chmielewski, R. Piwowarczyk, 08.06.2007 (KTC), [9], probably also O. kochii; 72 Chomęciska Małe, a xer. gras. on a hillside, ca. $0.5 \mathrm{~km} \mathrm{SE}$ of village buildings, at an intersection of field roads $(<5)$, $50^{\circ} 48^{\prime} 26^{\prime \prime} \mathrm{N}, 23^{\circ} 12^{\prime} 34^{\prime \prime}$ E, vid. P. Chmielewski, R. Piwowarczyk, 09.06.2007 [9]; 73 - Huszczka Duża, xer. gras. belonging to association Inuletum ensifoliae and in communities with Brachypodium pinnatum, on a vast calcareous slope $(<15)$, $50^{\circ} 50^{\prime} 10^{\prime \prime} \mathrm{N}, 23^{\circ} 19^{\prime} 11^{\prime \prime} \mathrm{E}$, leg. A. Cwener, 30.06.2006 (LBL) [9]; 81 - Niedzieliska, fringe communities on the edge of a juniper scrub complex, ca. $700 \mathrm{~m} \mathrm{~S}$ of village buildings (one specimen), $50^{\circ} 42^{\prime} 00^{\prime \prime} \mathrm{N}, 23^{\circ} 04^{\prime} 53^{\prime \prime} \mathrm{E}$, vid. A. Cwener, P. Chmielewski, 28.07.2009 [9]; 82 - Kąty II, initial xer. gras. near a dirt road from the Wymysłówka village to Wychody, on a midfield hill known as Wieprzecka Góra $(<10)$, $50^{\circ} 40^{\prime} 46^{\prime \prime} \mathrm{N}, 23^{\circ} 07^{\prime} 35^{\prime \prime} \mathrm{E}$; vid. R. Piwowarczyk, W. Michalczuk \& P. Chmielewski, 2006 [9]; Kąty n. Zamość, pine forest on humic chalky rendzina, leg. D. Fijałkowski, 05.06.1959 (LBL); sunny chalky slope, leg. D. Fijałkowski, 11.08.1965 (LBL); Kąty II, oak forest on chalk, leg. D. Fijałkowski, 29.06.1951 (LBL); Kąty II n. Zamość, Inuletum ensifoliae, leg. A. Brzeg, 04.08.1984 (POZ); vicinity of Zawada n. Zamość, on a baulk between arable fields, field, leg. D. Fijałkowski, 29.06.1951 (LBL); GF: 04 - Przecinka, xer. gras. on a chalky hillside (Kamienna hill), between Przecinka and Justynówka villages (>20), 50²9'22" N, 2329'37" E, vid. P. Chmielewski, 15.06.2008 [9]; 15 - Kolonia Korhynie, a fallow field on chalky rendzina, in the $\mathrm{W}$ part of the village. The locality was destroyed by ploughing in spring 2010. $50^{\circ} 25^{\prime} 41^{\prime \prime} \mathrm{N}$, $23^{\circ} 33^{\prime} 02^{\prime \prime}$ E, leg. P. Chmielewski, R. Piwowarczyk, 13.07.2008 (KTC) [9]; Kolonia Jarczów I, a fallow field in the W part of the village, $(<10), 50^{\circ} 26^{\prime} 03^{\prime \prime} \mathrm{N}, 23^{\circ} 33^{\prime} 46^{\prime \prime} \mathrm{E}$, vid. P. Chmielewski, 2008 [9]; Żurawce, an initial xer. gras. near the "Źurawce" ecol. site, on the slope of the Sołokija v. (>20), $50^{\circ} 23^{\prime} 33^{\prime \prime} \mathrm{N}, 23^{\circ} 33^{\prime} 35^{\prime \prime}$ E, vid. P. Chmielewski, 2007 [9]; Przeorsk, przydroże, vid. P. Chmielewski, 30.06.2011; 25 Machnów Stary, xer. gras. in "Machnowska Góra” res. (>10), $50^{\circ} 22^{\prime} 10^{\prime \prime} \mathrm{N}, 23^{\circ} 35^{\prime} 21^{\prime \prime} \mathrm{E}$; vid. P. Chmielewski, 2007 [9].

\section{Orobanche kochii}

AD: 05(?) - cfr., Lubusz Land, Bielice, escarpment on a roadside ditch, leg. H. Ratyńska, M. Wojterska, 18.06.2007 (POZ); DE: 11 - Łęg hamlet, between Burzenin and Szczawno, gras. on the left bank of the Warta river, $51^{\circ} 26^{\prime} 45^{\prime \prime} \mathrm{N}$, $18^{\circ} 48^{\prime} 47^{\prime \prime}$ E, 164 m, vid. P. Niedźwiedzki, 02.08 .2011 (phot.); between Wielka Wieś n. Burzenin and Borki forest (n. Winnica res.), abandoned fallow, excavation pit, on the right bank of the Warta river, $51^{\circ} 25^{\prime} 58^{\prime \prime} \mathrm{N}, 18^{\circ} 50^{\prime} 20^{\prime \prime} \mathrm{E}, 155 \mathrm{~m}$, vid. P. Niedźwiedzki, 02.08.2011 (phot.); 29 - E of SulejówPodklasztorze, on the right bank of the Radonka river (tributary of the Pilica river), on the side of an unfrequented road (overgrown with grass), by a grain field on one side and a low gras. on the other, (1 specimen), $51^{\circ} 21^{\prime} 55.3^{\prime \prime} \mathrm{N}$, $19^{\circ}$ 53'26.3" E, vid. P. Niedźwiedzki, 29.06.2011 (phot.); 57 - between Przedbórz and Radomsko [99]; 59 - cfr. Brzostek, Przedbórz distr., hill by the forest near the Brzostek PoliczkoChojna road, thermophilous gras., leg. M. Kurzac, 07.07.2010 (LOD, 154948); Góry Suche village near Góry Mokre village, W part, NNE-facing xer. gras. and scrubs $(>15)$, $51^{\circ} 01^{\prime} 45,57^{\prime \prime} \mathrm{N}, 1^{\circ} 58^{\prime} 24^{\prime \prime} \mathrm{E}, 279 \mathrm{~m}$, leg. R. Piwowarczyk,
03.05.2006 (KTC) [13]; 59/69 - Murawy Dobromierskie res. n. Dobromierz, edge of a former excavation pit and baulks (>10), 51 $00^{\prime} 34,9^{\prime \prime} \mathrm{N}, 19^{\circ} 54^{\prime} 37,2^{\prime \prime} \mathrm{E}, 273 \mathrm{~m}$, leg. R. Piwowarczyk, 04.06.2008 (KTC) [13]; 69 - Stara Wieś n. Góry Mokre village, xer. gras. (>10), leg. A. Adamiec, 2006, leg. R. Piwowarczyk, 20.07.2007 (KTC) [13]; 83 - CzęstochowaOstatni Grosz, fields, crops, grains, leg. F. Karo, 1865, 25.08.1874 (WA, $018913=28454 ; 018918=28440$ ) [100]; 94 - Skrajnica, Dolny Ostrówek hill, Olsztyn distr., limestone quarry, xer. gras., leg. J. Hereźniak, 21.08.1986 (LOD, 154405), [101]; 95 - Przymiłowice-Kotysów, Olsztyn distr. n. Częstochowa, midfield scrub, leg. J. Kołodziejek, 16.08.1987 (LOD, 084145), [101]; DF: 03 - between Woźniki and Gniazdów, NE slope of hill 359, near yellow route, steep

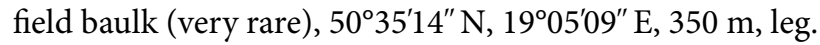
Ł. Krajewski, 28.07.2011 (KTC; Gniazdów; BabczyńskaSendek 1995, US); between Wojsławice and Cynków, hill 345 , W of road, secondary xer. gras., fallow rendzinas, $\mathrm{S}$ exp., (250), 50³4'11" N, 1907'25" E, 345 m, leg. Ł. Krajewski, 28.07.2011 (KTC), Wojsławice Duże, S margin, steep slopes (Babczyńska-Sendek 1996, US); 04 - Rzeniszów N, in front of chapel near junction of Koziegłówka road and KatowiceWarszawa motorway, secondary xer. gras. (very rare), $50^{\circ} 34^{\prime} 36,45^{\prime \prime} \mathrm{N}, 19^{\circ} 09^{\prime} 47,75^{\prime \prime} \mathrm{E}, 317 \mathrm{~m}$, leg. Ł. Krajewski, 28.07.2011 (KTC); Żarki E, Góra Parchowatka Mt (rocky hill 407), xer. gras., SW exp., (40), 50³7'28" N, 19²13'22" E, 390-395 m, leg. Ł. Krajewski, 24.09.2011 (KTC); 05 - Góra Włodowska SW (hill 410), NW slope, xer. gras. on field roadside, (10, close to $O$. lutea), $50^{\circ} 34^{\prime} 45^{\prime \prime} \mathrm{N}, 19^{\circ} 25^{\prime} 04,5^{\prime \prime} \mathrm{E}$, 375 m, leg. Ł. Krajewski, 07.09.2011 (KTC); 06 - Kolonia Hucisko E, xer. gras., SE slope, (15), 50³5'50" N, 19³0'26" E, 394 m, vid. Ł. Krajewski, 08.09.2014 (phot.); 14 - Markowice SW, fallows, mown meadows, field baulks, S exp., (125), $50^{\circ} 33^{\prime} 17^{\prime \prime} \mathrm{N}, 19^{\circ} 09^{\prime} 36^{\prime \prime} \mathrm{E}, 355$ m, leg. Ł. Krajewski, 28.07.2011 (KTC); Brudzowice W, hill 368, W slopes, xer. gras. on field baulk, (very rare), $50^{\circ} 30^{\prime} 15^{\prime \prime} \mathrm{N}, 19^{\circ} 10^{\prime} 37^{\prime \prime} \mathrm{E}, 340 \mathrm{~m}$, leg. . Krajewski, 23.07.2011 (KTC); 15 - Skałka N, hill Skałka, rendzina fallows, SW exp. (3, mixed with O. lutea), 50 $32^{\prime} 02.4^{\prime \prime}$ $\mathrm{N}, 19^{\circ} 24^{\prime} 22.5^{\prime \prime} \mathrm{E}, 370 \mathrm{~m}$, vid. Ł. Krajewski 26.10.2014, phot.; 16 - Włodowice, dry calcareous hill, leg. M. Molenda, 13.08.1978 (KTU, 25638); 23 - Sączów W, hill 333, N slopes, fallows with dominant C. scabiosa, SE, W exp., (10), $50^{\circ} 26^{\prime} 26^{\prime \prime} \mathrm{N}, 19^{\circ} 01^{\prime} 22^{\prime \prime} \mathrm{E}, 330 \mathrm{~m}$, leg. Ł. Krajewski, 29.07.2011 (KTC); Góra Siewierska S/Strzyżowice, Równa Góra Mt (hill

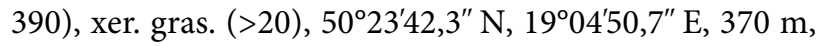
leg. R. Piwowarczyk, 05.06.2008 (KTC), Strzyżowice (Babczyńska-Sendek 1998 - US, 102); Strzyżowice NW, Krzasek (hill 372), steep S slopes, old limestone quarries, calcareous gras. Adonido-Brachypodietum pinnati, ThalictroSalvietum pratensis, S, SW exp. (20, mixed with O. lutea), $50^{\circ} 23^{\prime} 37,3^{\prime \prime} \mathrm{N}, 19^{\circ} 04^{\prime} 20^{\prime \prime} \mathrm{E}, 50^{\circ} 23^{\prime} 37,7^{\prime \prime} \mathrm{N}, 19^{\circ} 04^{\prime} 16^{\prime \prime} \mathrm{E}, 365-370$ m, vid. Ł. Krajewski 10.09.2010, 06.08.2012 (phot.); Rogoźnik, Bobrowniki distr., xer. gras., leg. M. Bosek, 03.08.1985 (KTU, 41265); Siemonia NE, Góra Korzystna Mt (hill 383), Cirsio-Brachypodion pinnati, fallows, S, NE, NW exp., (80 in 3 subpopulations), 370-380 m, leg. $€$. Krajewski, 03.09.2010 (KTC), Łubianki n. Siemonia, Góra Korzystna Mt, (Babczyńska-Sendek 1998 - US; Nowak 1997 - US, as O. lutea); Nowa Wieś, Łubianki, field baulk, leg. B. Hanak, 17.08.1996 (KTU, 99028), between Łubianki and 
Nowa Wieś, Góra Łubianki Mt (hill 398 m), Cirsio-Brachypodion pinnati, S exp., (25), 50²5'23" N, 1904'51" E, $385 \mathrm{~m}$, leg. Ł. Krajewski, 03.09.2010 (KTC); 24 - Przeczyce W, Bukowice (hill 314, $0.2 \mathrm{~km} \mathrm{~W}$ of dam), xer. gras. with numerous Peucedanum oreoselinum on old rendzina fallow, calcareous gras., N, S exp., (50), 50²6'18" N, 19¹0'05" E, 312-314 m, leg. Ł. Krajewski, 04.09.2013; Toporowice NE, Ostra Góra (hill 351), xer. gras., margin of termophilous scrubs, (100), $50^{\circ} 25^{\prime} 37^{\prime \prime} \mathrm{N}, 1^{\circ} 09^{\prime} 06,2^{\prime \prime} \mathrm{E}, 334 \mathrm{~m}$, leg. R. Piwowarczyk, 05.06.2008 (KTC), calcareous gras. under rocky steep slopes, fallow rendzinas on summit plateau, baulks, roadsides, $\mathrm{W}$,

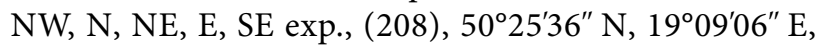
$50^{\circ} 25^{\prime} 38^{\prime \prime} \mathrm{N}, 19^{\circ} 09^{\prime} 09^{\prime \prime} \mathrm{E}, 50^{\circ} 25^{\prime} 44,7^{\prime \prime} \mathrm{N}, 19^{\circ} 09^{\prime} 01^{\prime \prime} \mathrm{E}, 320-$ 345 m, leg. Ł. Krajewski, 25.10.2009 (KTC; BabczyńskaSendek 1988 - US); between Toporowice and Stara Wieś, $0.5 \mathrm{~km}$ E of Ostra Góra Mt (hill 351), rendzina fallows with numerous C. scabiosa, SE exp., (15), 50²5'36" N, 1909'31" E, 305 m, vid. Ł. Krajewski 04.09.2013 (phot.); SiewierzChmielowskie E, calcareous sands with dominant C. scabiosa, SW exp., (very rare), 50 $26^{\prime} 68,9^{\prime \prime} \mathrm{N}, 19^{\circ} 12^{\prime} 18,1^{\prime \prime} \mathrm{E}, 320 \mathrm{~m}$, leg. Ł. Krajewski, 17.07.2011 (KTC); between Podwarpie and Podskale, hill 317, W slope, field baulk, (very rare, close to O. lutea, $200 \mathrm{~m}$ to O. elatior s.str.), $50^{\circ} 25^{\prime} 26^{\prime \prime} \mathrm{N}, 19^{\circ} 12^{\prime} 58^{\prime \prime} \mathrm{E}$, 312 m, leg. Ł. Krajewski 04.09.2013; DG, Podwarpie SE, fallow rendzina, $S W$ exp., (25), 50 $25^{\prime} 16,8^{\prime \prime} \mathrm{N}, 19^{\circ} 14^{\prime} 16,2^{\prime \prime} \mathrm{E}$, $315 \mathrm{~m}$, leg. Ł. Krajewski, 17.07.2011 (KTC); DGTrzebiesławice NW, $0.5 \mathrm{~km}$ W of cemetery, Adonido-Brachypodietum pinnati, (15), 50²6' $21^{\prime \prime} \mathrm{N}, 19^{\circ} 14^{\prime} 22^{\prime \prime} \mathrm{E}, 330 \mathrm{~m}$, leg. Ł. Krajewski, 17.07.2011 (KTC); DG, Ujejsce E, Góra Chendówka hill, calcareous gras., SW exp., (1, numerous O. lutea), $50^{\circ} 23^{\prime} 32^{\prime \prime} \mathrm{N}, 19^{\circ} 14^{\prime} 45^{\prime \prime} \mathrm{E}, 325 \mathrm{~m}$, vid. Ł. Krajewski 17.07.2011, phot.; 25 - Chruszczobród S, Gawronów/DG, Tucznawa-Bugaj, field baulk with numerous Peucedanum oreoselinum, overgrowing Prunus spinosa and Solidago, SE

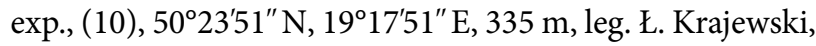
28.10.2009 (KTC), not found later; 26 - Zawiercie-Bzów, close to road to Podzamcze, fallows, $(<10), 50^{\circ} 28^{\prime} 07^{\prime \prime} \mathrm{N}$, 19³1'29" E, 432 m, vid. R. Piwowarczyk 07.2013; Ogrodzieniec S, near Dół Zarazki, fallow with Prunus spinosa scrubs, leg. P. Kurek, 08.2009 (KTC); Grabowa NE, Wierzgóry (hill 423), calcareous gras., SW, E, SE exp., (50, rarely mixed with O. lutea), $50^{\circ} 23^{\prime} 46^{\prime \prime} \mathrm{N}, 19^{\circ} 28^{\prime} 04^{\prime \prime} \mathrm{E} ; 50^{\circ} 23^{\prime} 34^{\prime \prime} \mathrm{N}, 19^{\circ} 27^{\prime} 44,5^{\prime \prime} \mathrm{E}$; $50^{\circ} 23^{\prime} 28^{\prime \prime} \mathrm{N}, 1^{\circ} 28^{\prime} 11^{\prime \prime} \mathrm{E}, 390-410 \mathrm{~m}$, leg. Ł. Krajewski, 18.09.2009, 02.10.2009 (KTC); 29 - Uniejów-Rędziny, fallow between the forest $\mathrm{n}$. the Tunel railway station and the Biała Góra res., between the road to Kępa and the forest, fallow behind a single house, leg. M. Bogdański, 27.07.1988 (KRA, 0171466); Tunel n. Miechów, steppe slope, leg. A. Jasiewicz, 01.07.1956 (KRAM, 414025); NEE of Kępie, xer. gras. near railway line (1 shoot), $50^{\circ} 27^{\prime} 37^{\prime \prime} \mathrm{N}, 1^{\circ} 57^{\prime} 49^{\prime \prime} \mathrm{E}, 345 \mathrm{~m}$, vid. B. Binkiewicz, 19.08.2005; 32 - Piekary Śląskie-Szarlej, NE of railway station, xer. grass on old calamine quarries and

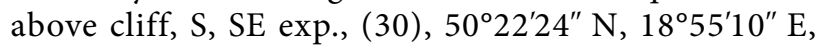
$50^{\circ} 22^{\prime} 29^{\prime \prime} \mathrm{N}, 18^{\circ} 55^{\prime} 25^{\prime \prime} \mathrm{E}, 290-300$ m, leg. Ł. Krajewski, 29.07.2011 (KTC), (=Scharley; as O. lutea in [55]); Bobrowniki-Namiarki, xer. gras., vid. Ł. Depa, P. Siwy, A. Szczepańczyk, 07.2009, phot.; between Bobrowniki and Namiarki, E of A1 motorway, xer. gras. on steep field baulk, S exp., (very rare), 50²2'39,4" N, 18 58'12,7" E, 295 m, leg. Ł. Krajewski, 07.07.2011 (KTC); Bobrowniki S, 0.2 km NWW of cemetery, W slopes $\mathrm{N}$ of field road, calcareous gras. by old limestone quarries, roadsides, SW, W exp., (25), $50^{\circ} 22^{\prime} 37^{\prime \prime} \mathrm{N}, 18^{\circ} 59^{\prime} 33^{\prime \prime} \mathrm{E}, 300-310 \mathrm{~m}$, leg. Ł. Krajewski, 13.07.2011 (KTC); 33 - Rogoźnik, xer. gras., leg. M. Bosek 03.08.1985 (KTU, 41265); Wojkowice, Kolonia Maszyńska, xer. gras. on baulk n. former "Saturn" cement plant (Będzin, Kolonia Maszyńska), leg. A. Sendek, 06.09.1976 (KTU, 34397; as O. minor in [103]); Wojkowice, hill between Kolonia Maszyńska and Brynica v., secondary xer. gras., W, SW exp., (40), 50²1'38" N, 1901'14" E, 275-280 m, leg. Ł. Krajewski, 01.07.2011 (KTC); Wojkowice-Żychcice/Bobrowniki NW, hill 329, summit and NE slopes, NE, SE, S, SW exp., (90), 50²2'36" N, 1900'28" E, 322-328 m, leg. $Ł$. Krajewski, 13.07.2011 (KTC); Wojkowice Komorne, Żychcice, field baulk close to "Saturn" cement plant, leg. A. Sendek, 06.09.1976 (KTU, 34396); Wojkowice S, between "Jowisz" former coal mine and Brynica v., fallow rendzinas, SW, S, SE, E exp., (150), 50²1'08" N, 1902'53" E, 285-295 m, leg. Ł. Krajewski, 01.07.2011 (KTC); Będzin, Grodziec W-Boleradz, overgrowing field baulks with numerous $P$. oreoselinum and C. scabiosa, W exp., (20), 50²1'05,6" N, 1904'02,9” E, 302 m, leg. Ł. Krajewski, 13.07.2011 (KTC); Będzin, Grodziec NE, Góra Świętej Doroty (hill 381), oat field, leg. K. Zagórna, 08.1969 (LOD, 154406), NW slope, Adonido-Brachypodietum pinnati, (very rare), $50^{\circ} 21^{\prime} 09^{\prime \prime} \mathrm{N}$, $19^{\circ} 05^{\prime} 48^{\prime \prime}$ E, 350 m, leg. Ł. Krajewski, 13.07.2011 (KTC; Nowak 1997 - US, as O. lutea); Będzin-Małobądz, hill 305, $\mathrm{W}$ of iron radio tower, $\mathrm{S}$ of field road, calcareous xer. gras. overgrowing Solidago, W exp., (20; 12 in one clump), $50^{\circ} 18^{\prime} 27^{\prime \prime} \mathrm{N}, 19^{\circ} 07^{\prime} 17^{\prime \prime} \mathrm{E}, 300 \mathrm{~m}$, leg. .. Krajewski, 17.07.2010 (KTC); 34 - Będzin, Warpie-Wschód, hill 301, secondary xer. gras. close to old limestone quarries, $(15$, mixed with O. lutea), $50^{\circ} 18^{\prime} 59^{\prime \prime} \mathrm{N}, 19^{\circ} 09^{\prime} 13^{\prime \prime} \mathrm{E}, 297 \mathrm{~m}$, leg. Ł. Krajewski, 27.07.2009 (KTC), later not found; DG-Gołonóg, Mała Góra Gołonoska (hill 334), calcareous xer. gras. overgrowing scrub, W, SW, S exp., (2, 25, 10, mixed with O. lutea, close to locality $O$. elatior s.str.), $50^{\circ} 20^{\prime} 05^{\prime \prime} \mathrm{N}, 19^{\circ} 14^{\prime} 22^{\prime \prime} \mathrm{E}$; $50^{\circ} 20^{\prime} 03,8^{\prime \prime} \mathrm{N}, 19^{\circ} 14^{\prime} 31,5^{\prime \prime} \mathrm{E}, 324-332 \mathrm{~m}$, leg. Ł. Krajewski, 04.08.2009 (KTC), vid. Ł. Krajewski 2009-2013; DG-Ujejsce, xer. gras., leg. T. Nowak, 14.07.1994 (KTU, 99016); DG, Pańska Góra (hill 337), between Ujejsce and Ząbkowice, calcareous gras. on summit mound, (very rare in numerous O. lutea), $50^{\circ} 23^{\prime} 03,5^{\prime \prime} \mathrm{N}, 19^{\circ} 14^{\prime} 48,5^{\prime \prime} \mathrm{E}, 335 \mathrm{~m}$, vid. $\mathrm{E}$. Krajewski 2009, leg. Ł. Krajewski, 17.07.2011 (KTC); DG, NE of Pańska Góra hill, fallow rendzina, S exp., (very rare), $50^{\circ} 23^{\prime} 08,6^{\prime \prime} \mathrm{N}, 19^{\circ} 14^{\prime} 56,3^{\prime \prime} \mathrm{E}, 330 \mathrm{~m}$, leg. Ł. Krajewski, 17.07.2011 (KTC); 35 - DG, Ząbkowice E, S of dolomite quarry, close to Gościniec Pasieka route, old rendzina fallows overgrowing Crataegus and Solidago, (10-15; mixed with O. lutea), $50^{\circ} 22^{\prime} 05,3^{\prime \prime} \mathrm{N}, 19^{\circ} 17^{\prime} 29^{\prime \prime} \mathrm{E}, 344 \mathrm{~m},(5), 50^{\circ} 22^{\prime} 06^{\prime \prime} \mathrm{N}$, $19^{\circ} 17^{\prime} 45^{\prime \prime} \mathrm{E}, 356 \mathrm{~m},(25), 50^{\circ} 22^{\prime} 17,5^{\prime \prime} \mathrm{N}, 1^{\circ} 16^{\prime} 57^{\prime \prime} \mathrm{E}, 340 \mathrm{~m}$, leg. Ł. Krajewski, 13.09.2009 (KTC), vid. Ł. Krajewski, 13.11.2012, 4.01.2014, vid. R. Piwowarczyk 2014, not found 2010-2011, DG-Ząbkowice, Góra Kamionka hill [104]; DG, Łęka NW, hill 361 (Łosy), xer. gras. overgrowing Prunus spinosa, (very rare, mixed with $O$. elatior s.str., close to

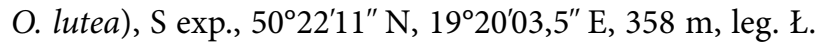
Krajewski, 06.09.2013 (KTC), not observed 2008-2011; DG, Łosień N, W of medieval Trakt Siewierski route, $25 \mathrm{~m}$ S Las Bienia forest, old fallows, $\mathrm{S}$ exp. (very rare), $50^{\circ} 21^{\prime} 38^{\prime \prime} \mathrm{N}$, 
$19^{\circ} 19^{\prime} 16^{\prime \prime}$ E, 370 m, leg. Ł. Krajewski, 27.09.2009 (KTC); DG-Łosień N, hill 390, NW slopes, field roadside with xer. gras., (very rare), $50^{\circ} 21^{\prime} 28^{\prime \prime} \mathrm{N}, 19^{\circ} 19^{\prime} 40,25^{\prime \prime} \mathrm{E}, 380 \mathrm{~m}$, vid. . Krajewski 06.08.2009, leg. Ł. Krajewski, 01.08.2010 (KTC); DG-Łosień, $1 \mathrm{~km} \mathrm{S,} \mathrm{(10,} \mathrm{mixed} \mathrm{with} \mathrm{numerous} \mathrm{O.} \mathrm{lutea),}$ xer. calamine gras., SW exp., 50²0'29,5" N, 19²19'27,5" E, 355 m, leg. Ł. Krajewski, 06.08.2009 (KTC, later not found); Sławków W, Góra Kołdaczka Mt (hill 322), N slope, old rendzina fallow overgrowing Libanotis, (very rare, close to O. lutea), $50^{\circ} 18^{\prime} 05,4^{\prime \prime} \mathrm{N}, 19^{\circ} 22^{\prime} 33^{\prime \prime} \mathrm{E}, 318 \mathrm{~m}$, leg. Ł. Krajewski, 15.09.2009 (KTC); Sławków E, Świnia Góra Mt (hill 312), xer. gras. overgrowing scrubs above old limestone quarry and road Sławków-Podlipie, (very rare, $100 \mathrm{~m} \mathrm{E} \mathrm{of} \mathrm{O.} \mathrm{lutea),}$ $50^{\circ} 17^{\prime} 48,8^{\prime \prime} \mathrm{N}, 19^{\circ} 24^{\prime} 28,1^{\prime \prime} \mathrm{E}, 308$ m, leg. Ł. Krajewski, 16.09.2009 (KTC), later not found; 36 - DG, Błędów, Góra Kamieniec (Młyńska, hill 341), W side of asphalt road crossing $\mathrm{N}$ slope, secondary xer. gras. on fallow rendzinas, (20, mixed with O. elatior s.str. in upper part), $50^{\circ} 20^{\prime} 58^{\prime \prime} \mathrm{N}$, $19^{\circ} 27^{\prime} 51^{\prime \prime}$ E, 325-330 m, leg. Ł. Krajewski, 26.09.2009, 10.07.2011 (KTC), vid. Ł. Krajewski, 06.09.2013; 38 Gołaczewy Stara Wieś, xer. gras. n. quarry, NE exp., $(<5)$, $50^{\circ} 21^{\prime} 52,9^{\prime \prime} \mathrm{N}, 19^{\circ} 42^{\prime} 52,3^{\prime \prime}$ E, 397 m, vid. R. Piwowarczyk, 31.09.2011; 44 - Jaworzno-Długoszyn E, hill with iron cross SE of church, secondary gras. Cirsio-Brachypodion pinnati, SW exp., $(40,30), 50^{\circ} 14^{\prime} 43^{\prime \prime} \mathrm{N}, 19^{\circ} 15^{\prime} 53^{\prime \prime} \mathrm{E}, 280 \mathrm{~m}$, leg. . Krajewski, 04.08.2010, 05.08.2011 (KTC, also f. citrina in 2010 and 2011); 45 - Jaworzno, Szczakowa-Gadlin, hill W of cemetery, horse pasture, small patch of xer. gras. sourrounded by Solidago and Calamagrostis, (20), 50 $14^{\prime} 05^{\prime \prime} \mathrm{N}$, $19^{\circ} 17^{\prime} 48^{\prime \prime}$ E, 285 m, leg. Ł. Krajewski, 07.08.2010 (KTC); Jaworzno-Ciężkowice, arable fields - fallow, leg. J. Nowak, 24.07.1953 (CHRZ); Jaworzno-Ciężkowice, Góra Wielkanoc Mt (hill 331), Thalictro-Salvietum pratensis, S, SW exp., (25), $50^{\circ} 12^{\prime} 41^{\prime \prime} \mathrm{N}, 1^{\circ} 20^{\prime} 32^{\prime \prime} \mathrm{E}, 318-320$ m, leg. Ł. Krajewski, 08.08.2010 (KTC); Jaworzno NE, hill 341 under power line, E of Góra Przygoń hill, mesophilous gras. Thalictro-Salvietum pratensis varying to Origano-Brachypodietum pinnati, NW, W exp., (45), 50 $12^{\prime} 28^{\prime \prime} \mathrm{N}, 1^{\circ} 23^{\prime} 18^{\prime \prime} \mathrm{E}, 340 \mathrm{~m}$, leg. Ł. Krajewski, 13.08.2010 (KTC); 46 - Podlipie S, hill 362 m, xer. gras. on old fallow rendzinas, (very rare in numerous O. lutea), $50^{\circ} 17^{\prime} 32^{\prime \prime} \mathrm{N}, 19^{\circ} 25^{\prime} 45^{\prime \prime} \mathrm{E}, 360 \mathrm{~m}$, leg. Ł. Krajewski, 16.09.2009 (KTC); Krążek S, hill 335, poor calamine gras./ fallow rendzina, slightly sandy, overgrowing Pinus, SW, W exp., (very rare), $50^{\circ} 17^{\prime} 17^{\prime \prime} \mathrm{N}, 19^{\circ} 27^{\prime} 18^{\prime \prime} \mathrm{E}, 330 \mathrm{~m}$, leg. $€$. Krajewski, 18.09.2011 (KTC); Olkusz NW, Góra Pomorska (hill 418), poor xer. gras. on fallow rendzinas, SW, W exp. (10), $50^{\circ} 17^{\prime} 34^{\prime \prime} \mathrm{N}, 19^{\circ} 33^{\prime} 08^{\prime \prime} \mathrm{E}, 405-415$ m, leg. Ł. Krajewski, 15.09.2011 (KTC); 47 - Sikorka n. Olkusz, leg. A. Zalewski, 27.07.1893 (WA, $018895=28421,018894=28450$ ); Witeradów SE, Góra Kadzielnia (hill 417) and to E, xer. gras.,

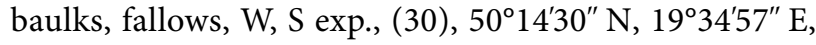
410-420 m, leg. Ł. Krajewski, 13.09.2011 (KTC); Kosmolów N, S of Podłużne forest, closed Eagles' Nests red trail, dry meadow, xer. gras. on fallow rendzinas, (50), $50^{\circ} 16^{\prime} 56^{\prime \prime} \mathrm{N}$, $19^{\circ} 38^{\prime} 54^{\prime \prime}$ E, $50^{\circ} 16^{\prime} 52,4^{\prime \prime} \mathrm{N}, 19^{\circ} 38^{\prime} 52^{\prime \prime} \mathrm{E}, 400-420 \mathrm{~m}$, leg. . Krajewski, 10.07.2011 (KTC); 53 - Lędziny SW, Góra Klimont (hill 302), SW of St. Clemens' church, xer. gras., (20, mixed with O. elatior s.str.), 50 $07^{\prime} 13^{\prime \prime} \mathrm{N}, 19^{\circ} 06^{\prime} 08^{\prime \prime} \mathrm{E}, 295 \mathrm{~m}$, leg. Ł. Krajewski, 13.09.2010 (KTC); 54 - Dziećkowice (Grabina b. Dzieckowitz), as var. kochii [54,55,105]; between
Imielin-Pasieczki and Mysłowice-Dziećkowice, hill 310, S of A4 motorway, calcareous xer. gras., S exp., (15, close to O. elatior s.str.), 5009'50" N, 19 $12^{\prime} 37^{\prime \prime} \mathrm{E}, 300-307 \mathrm{~m}$, leg. $\mathrm{.}$. Krajewski, 04.09.2010 (KTC), Imielin, Pasieczki [55,106], Myslovitz [27]; 55 - Jaworzno-Śródmieście, above old limestone quarry NW of Góra Grodzisko hill, overgrowing xer. gras., SW exp., (20, mixed with numerous O. lutea), $50^{\circ} 11^{\prime} 20^{\prime \prime} \mathrm{N}, 19^{\circ} 17^{\prime} 33^{\prime \prime} \mathrm{E}, 315$ m, leg. Ł. Krajewski, 04.08.2010 (KTC); Jaworzno NE, hill W of Trzebinia-Stara Maszyna, fallows with dominant C. scabiosa, S, SW exp., (10), $50^{\circ} 12^{\prime} 13^{\prime \prime} \mathrm{N}, 19^{\circ} 23^{\prime} 33^{\prime \prime} \mathrm{E}, 347 \mathrm{~m}$, leg. Ł. Krajewski, 13.08.2010 (KTC), 2011 ploughed (=Siersza, Stara Maszyna, W of village; Chmiel 1993 - US); between Chrzanów and Balin, Wójtowa Góra hill on S side, baulk, leg. P. Grzegorzek, 21.09.1985 (CHRZ); 56 - Trzebinia-Podbuczyna, hill under power line between Podbuczyna and Podkrystynów, Adonido-Brachypodietum pinnati, SW, S exp., (15), 50¹0'44" N, $19^{\circ} 25^{\prime} 59^{\prime \prime}$ E, 372 m, leg. Ł. Krajewski, 24.08.2010 (KTC); Trzebinia E, hill $375 \mathrm{~m}$, NE of the ZWM district, ThalictroSalvietum pratensis/Prunetalia spinosae, SW exp., (very rare, mixed with O. lutea), 5009' $42^{\prime \prime} \mathrm{N}, 19^{\circ} 28^{\prime} 44^{\prime \prime} \mathrm{E}, 355 \mathrm{~m}$, leg. Ł. Krajewski, 24.08.2010 (KTC); 58 - Dolina Kobylańska valley [80] (phot.); 66 - Bolęcin, n. Skałka Triasowa, vid. P. Grzegorzek, 01.08 .2012 (phot.); Grojec, Alwernia distr., xer. gras. on the hillside between the hamlets Brandyska and Wymiarki, $50^{\circ} 05.621^{\prime} \mathrm{N}, 19^{\circ} 33.080^{\prime} \mathrm{E}, 353 \mathrm{~m}$, leg. B. Binkiewicz, 26.07.2014 (KTC); EF: 00 - between Sędziszów and Sosnowiec, xer. gras. (>10), leg. B. Piwowarski, 28.07.2011 (KRA); 04 - Gartatowice, xer. gras., fallows, on gypsum (<100), 50³4'34" N, 20³7'33" E, 237 m, vid. R. Piwowarczyk 2012-2013, leg. M. Nobis, 2012 (KRA) [13]; between Chomentówek and Sędziejowice, xer. gras. $(<10), 50^{\circ} 34^{\prime 2} 23^{\prime \prime} \mathrm{N}$, $20^{\circ} 39^{\prime} 44^{\prime \prime}$ E; vid. R. Piwowarczyk 2012-2013 [13]; Samostrzałów SSE, xer. gras., fallows, $(<5), 50^{\circ} 35^{\prime} 16^{\prime \prime} \mathrm{N}$, 2038'33" E, 248 m, vid. R. Piwowarczyk, 09.07.2013; 07 Jabłonica, xer. gras., leg. A. Pierścińska, 14.05.2009 (KRA); Jabłonica, Jabłonickie Mts, dry meadow, leg. A. Pierścińska, 09.09.2009 (KRA) [13]; NW of Szydłów, xer. gras. on a hill known as Lisi Kamień (>10), 50³6'10,25" N, 2059'35,27" E, 274 m, leg. M. Gwardjan, 2010 (KTC) [13]; Kotuszów, rye cultivation; leg. M. Faniczak, 19.07.1979 (KRA, 0233676); 13 - Góry Pińczowskie Mts, NW of Pińczów, wastelands, xer. gras. (>10), 50³2'08,4" N, 20³0'46" E, 219 m, leg. R. Piwowarczyk, 09.06.2009 (KTC) [13]; 14 - NW of the road from Pasturka village to the Las Pasturski forest, xer. gras.,

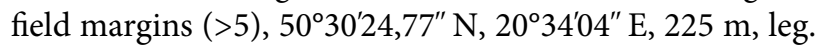
R. Piwowarczyk, 14.07.2008 (KTC) [13]; Wełecz n. Busko Zdrój, S-facing xer. gras. on a hill by a hardened road from Wełecz towards Siesławice (>20), 50²8'14,92" N, 20 $41^{\prime} 12^{\prime \prime} \mathrm{E}$, $261 \mathrm{~m}$, leg. R. Piwowarczyk, 21.07.2006 (KTC) [13]; 15 Łagiewniki n. Busko Zdrój, S and SW-facing xer. gras. (Zimne Wody res.; <10), 50²8'58,72" N, 2044'00" E, $254 \mathrm{~m}$, leg. R. Piwowarczyk, 21.07.2006 (KTC) [13]; 24 Krzyżanowice res. n. Gacki, S part, xer. gras. and wasteland (>10), 50²7'11,65" N, 20³4'04,92" E, 219 m, vid. R. Piwowarczyk, 2007 [13]; Skotniki Górne res. n. Skotniki Górne village, xer. gras. between road and railway lines, $\mathrm{S}$ and SW-facing, sporadically N and NE ( $>50)$, leg. R. Piwowarczyk, 07.2007 (KTC) [13]; Skorocice res. n. Skorocice village, xer. gras. (>10), vid. R. Piwowarczyk, 2007 [13]; Wola 
Zagojska, dry hill, leg. I. Latkowska, 24.07.2006 (KTC); 25 - Żerniki Górne, xer. gras. (>10), 50²7'29" N, 2047'28" E, 260 m, leg. M. Nobis, 2009 (KRA) [13,107]; xer. gras. located on the slope of the road leading through Żerniki Górne, $50^{\circ} 27^{\prime} 29,45^{\prime \prime} \mathrm{N}, 20^{\circ} 47^{\prime} 26,1^{\prime \prime}$ E, vid. I. Dembicz, Ł. Kozub, 02.07.2013, phot.; S of Ostra Góra ecol. site, S of Pęczelice, S-facing wastelands and field margins (>10), 50 $26^{\prime} 34^{\prime \prime} \mathrm{N}$, $20^{\circ} 47^{\prime} 05^{\prime \prime}$ E, 239 m, leg. R. Piwowarczyk, 13.07.2010 [13,14]; A hill S of the Łatanice-Hołudza road, xer. gras. (>30), 50²4'54,8" N, 2042'25,3" E, 197 m, leg. R. Piwowarczyk, 30.09.2009 (KTC) [13]; Przęślin res. n. Chotel Czerwony,

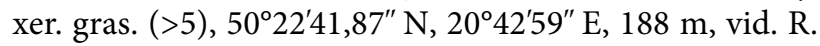
Piwowarczyk, 2006 [13]; 31 - Opalonki res., xer. gras., leg. D. Wołkowycki, 04.08.2010 (3377, D. Wołkowycki private herbarium); 32 - Pałecznica, xer. gras., leg. K. Towpasz, 08.07.2003; vicinity of Działoszyce, gypsum sink area on a slope between Szczotkowice and Pierocice, leg. T. Tacik, 09.08.1957 (KRAM 086091, 014848); 35 - Górki Pierwsze, xer. gras., on gypsum, roadsides, on both sides of the road from the Szczerbaków-Strążyska dirt road $(>10)$, $50^{\circ} 20^{\prime} 55,03^{\prime \prime} \mathrm{N}, 20^{\circ} 44^{\prime} 01^{\prime \prime} \mathrm{N}, 178 \mathrm{~m}, 50^{\circ} 20^{\prime} 54,72^{\prime \prime} \mathrm{N}$, $20^{\circ} 44^{\prime} 02^{\prime \prime} \mathrm{E}, 179 \mathrm{~m}$, leg. R. Piwowarczyk, 2006 (KTC) [13]; 41 - Gniazdowice, gypsum slope, leg. K. Towpasz, 11.07.1995, 29.06.1998 (KRA); 43 - Kazimierza Wielka, W part, between baulk and escarpment, leg. K. Towpasz, 11.07.1997 (KRA); 44 - Kaczkowice n. Kazimierza Wielka, leg. K. Towpasz, 21.06.1999 (KRA), vid. R. Piwowarczyk, 2008 [13]; 53 Książnice Małe n. Koszyce, gras. on a baulk, leg. K. Towpasz, 26.06.1999 (KRA); EE: 38 - N of Krzyżanowice, xer. gras. by a mid-field limestone excavation pit, leg. M. Nobis, 19.07.2000 (KRA, 0318683, 0318684) [13,108]; 46 - SSW of the Młodzawy estate in Skarżysko-Kamienna, between E side of the roadside and a forest complex $(>10)$, $51^{\circ} 05^{\prime} 19,88^{\prime \prime} \mathrm{N}, 20^{\circ} 52^{\prime} 33^{\prime \prime} \mathrm{E}, 269 \mathrm{~m}$, vid. Ł. Maślikowski, 2007 (phot.); $48-500 \mathrm{~m} \mathrm{~N}$ of the E part of Seredzice village [108]; 56 - Piaski n. Parszów, margin of a pine forest $\mathrm{W}$ of Piaski (2), $51^{\circ} 05^{\prime} 14,3^{\prime \prime} \mathrm{N}, 20^{\circ} 55^{\prime} 09^{\prime \prime} \mathrm{E}, 244 \mathrm{~m}$, vid. M. Fałdziński, 2008 (phot.); 61 - NNW of Skałka Polska n. Ewelinów, xer. gras. and thermophilous scrubs on a $\mathrm{S}$ and SW-facing hill, $50^{\circ} 57^{\prime} 06^{\prime \prime} \mathrm{N}, 20^{\circ} 10^{\prime} 03^{\prime \prime} \mathrm{E}, 250 \mathrm{~m}$, leg. R. Piwowarczyk, 09.07.2007 (KTC) [13]; 64 - Zachełmie n. Zagnańsk, xer. gras. on the edges of a closed quarry n. Chełmowa hill $(<20)$, $50^{\circ} 58^{\prime} 10^{\prime \prime} \mathrm{N}, 20^{\circ} 41^{\prime} 28^{\prime \prime} \mathrm{E}, 354 \mathrm{~m}$, leg. R. Piwowarczyk, 01.09.2005, leg. M. Nobis, A. Nobis, 2008 (KRA) [13]; 67 - Sniadka Druga, xer. gras. on the right slope of the Psarka river, so-called Wymysłowskie Doły, SW-facing $(<50)$, $50^{\circ} 57^{\prime} 13,22^{\prime \prime} \mathrm{N}, 21^{\circ} 00^{\prime} 45^{\prime \prime}, 252 \mathrm{~m}$, vid. A. T. Halamski, R. Piwowarczyk, 04.07.2006, leg. R. Piwowarczyk, 05.08.2008 (KTC) [13]; 74 - Kielce, a fallow behind the Institute of Chemistry, Jan Kochanowski University, Świętokrzyska street (3), 5052'53" N, 20³9'31" E, 289 m, leg. B. Maciejczak, 2008 (KTC), vid. B. Piwowarski, 2009 [13]; 75 - Between Górno and Górno Zawada, xer. gras. on a hill S of a dirt road $(>20)$, $50^{\circ} 50^{\prime} 38,3^{\prime \prime} \mathrm{N}, 20^{\circ} 48^{\prime} 02,3^{\prime \prime} \mathrm{E}, 279 \mathrm{~m}$, leg. R. Piwowarczyk, 08.2009 (KTC) [13]; 84 - S of Podgórze n. Bilcza, fallows and xer. gras. NNW of an old warehouse, $50^{\circ} 46^{\prime} 57,4^{\prime \prime} \mathrm{N}$, $20^{\circ} 35^{\prime} 48^{\prime \prime}$ E, $271 \mathrm{~m}$, vid. M. Fałdziński, 2008; Folwark n. Bilcza, gras., xer. scrub, fallows W and NW of a bus stop on the Kielce road, a few populations: W of the bus stop in Bilcza and of the road towards Kuby Młyny village (>20), $50^{\circ} 46^{\prime} 49,28^{\prime \prime} \mathrm{N}, 20^{\circ} 36^{\prime} 59^{\prime \prime} \mathrm{E}, 256 \mathrm{~m}$, NW of the bus stop in Bilcza and S of Marmurowa street (>150), 50 $46^{\prime} 58,91^{\prime \prime} \mathrm{N}$, 20³6'39" E, 253 m, vid. M. Fałdziński, 2008, leg. R. Piwowarczyk, 2008 (KTC) [13]; SSW of Kowala Mała, wastelands around a closed warehouse, NEE of Sukowianowa hill

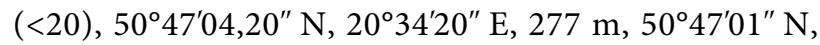
$20^{\circ} 34^{\prime} 35^{\prime \prime}$ E, 277 m, vid. M. Fałdziński, 23.07.2007; 87 Łagów, Dule Gorge, xer. gras. on the Zbójecka Cave, S,

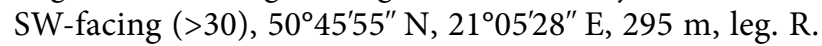
Piwowarczyk, 17.08.2006 (KTC), vid. B. Sępioł 2012, vid. R. Maniarski 2013 (phot.) [13]; Łagów, xer. gras. SE Zapłotnia

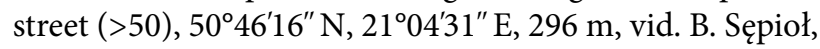
06.08.2013 (phot.); NWW of Zagościniec n. Łagów, xer. gras.

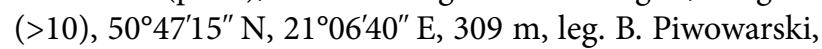
2010 (KTC); $150 \mathrm{~m} \mathrm{~N}$ of the Łagów-Nowy Staw road, xer.

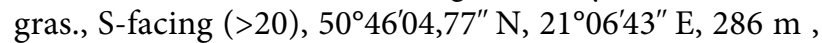
leg. R. Piwowarczyk, 17.08.2006 (KTC) [13]; 97 - Chańcza n. Raków, fallow NE of Chańcza $(>5), 50^{\circ} 39^{\prime} 01,67^{\prime \prime} \mathrm{N}$, $21^{\circ} 03^{\prime} 34^{\prime \prime} \mathrm{E}, 239 \mathrm{~m}$, vid. M. Fałdziński, 2009; FC: 97 - thermophilous gras., W of Drohiczyn, SE of Runice, (1), $52^{\circ} 23^{\prime} 57,4^{\prime \prime} \mathrm{N}, 22^{\circ} 37^{\prime} 50,51^{\prime \prime} \mathrm{E}$, vid. W. Heise, P. Naks, 26.08.2014 (phot.); FE: 24 - Iłki n. Celejów, Puławy distr., baulk, leg. research camp of a Łódź University student society, T. Załuski, 31.07.1971 (LOD, 13210); 54 - Sosnowa Wola n. Dzierzkowice, rendzina field, leg. B. Sałata, 11.07.1964 (LBL); 62 - Wesołówka, fallows, baulks and xer. gras. by the border of the Vistula v. ("Modrzywka"; $>30$ ), $50^{\circ} 58^{\prime} 41,9^{\prime \prime} \mathrm{N}, 21^{\circ} 47^{\prime} 47,2^{\prime \prime} \mathrm{E}, 170 \mathrm{~m}$, vid. R. Piwowarczyk, 1999-2013; leg. R. Piwowarczyk, 29.06.2005, 01.08.2010 (KTC) [9,13,14,109]; FE: 23 - Męćmierz, xer. gras. on the slopes of a vast ravine (one specimen), $51^{\circ} 18^{\prime} 07^{\prime \prime} \mathrm{N}$, $21^{\circ} 54^{\prime} 02^{\prime \prime}$ E, vid. R. Piwowarczyk \& P. Chmielewski, 26.07.2009 [9,14]; 27 - Rury n. Lublin, in sown fields behind cemetery, leg. F. Karo, 21.07.1881 (WA, $018911=28451)$; 60 - Boria, cz. S, xer. gras. (<100), 5058' $15^{\prime \prime} \mathrm{N}, 21^{\circ} 32^{\prime} 53^{\prime \prime} \mathrm{E}$, 167 m, vid. B. Sępioł, 27.06.2013, leg. R. Piwowarczyk, 29.06.2013, vid. R. Piwowarczyk, 07.2014 (with f. citrina, 2013-2014); 73 - Opoka Duża, fallow field bordering on the steep slopes of the Vistula v., overgrown with dense thermophilous scrub, ca. $1 \mathrm{~km} \mathrm{NW}$ of the village $(<5)$, $50^{\circ} 51^{\prime} 58^{\prime \prime} \mathrm{N}, 21^{\circ} 51^{\prime} 23^{\prime \prime} \mathrm{E}$, vid. P. Chmielewski, 14.04.2009 [9]; 79 - Elizówka, midfield initial xer. gras. and scrub on hillsides, ca. $0.5 \mathrm{~km}$ of village buildings (two specimens), $50^{\circ} 51^{\prime} 37^{\prime \prime} \mathrm{N}, 22^{\circ} 44^{\prime} 07^{\prime \prime} \mathrm{E}$, vid. P. Chmielewski, R. Piwowarczyk, 2008 [9]; FF: 00 - cfr., Beszyce, xer. gras., leg. A. Pierścińska, 23.05.2009 (KRA); 90 - Kołaczyce, gras., leg. K. Towpasz, 06.08.1985 (KRA); GD: 00 - in thermophilous gras. E of Osłów, 9 plants parasitic on C. scabiosa noted in 2011 ([110] and phot.); GE: 13 - Tarnów in Chełm region, on baulks in clay fields, leg. K. Łapczyński, 18?? (WA, 018864 = 28390); 23 - cfr. vicinity of Chełm, on baulks under Góra Stawska hill, n. Staw village, leg. F. Karo, 28.06.1883 (WA, $018926=28449) ; 34$ - Chełm, allotments, fields, leg. $\mathrm{H}$. Koporska, 07.1932 (LBL); 45 - Wólka Leszczańska, calcareous slope, leg. D. Fijałkowski, 30.07.1949 (LBL); 55 - Turowiec, a vast complex of initial xer. gras. and juniper scrub, ca. $1.5 \mathrm{~km} \mathrm{~N}$ of the cemetery near Turowiec and Popówka villages (<5), 50 $58^{\prime} 00^{\prime \prime} \mathrm{N}, 23^{\circ} 38^{\prime} 12^{\prime \prime} \mathrm{E}$, vid. P. Chmielewski, 2007 [9]; 62 - Tarnogóra, xer. gras. of Thalictro-Salvietum pratensis association on a loess slope $(>5), 50^{\circ} 53^{\prime} 42^{\prime \prime} \mathrm{N}$, 
$23^{\circ} 08^{\prime} 09^{\prime \prime}$ E, vid. A. Cwener, 2007 [9]; 64 - Wysokie n. Skierbieszów, sunny loes slope, leg. D. Fijałkowski, 15.07.1965 (LBL); 65 - cfr., Wola Uchańska, in a cultivation (rendzina), leg. M. Sowińska, 26.07.1961 (LBL); 74 - Wolica Uchańska, a xer. gras. and a fallow field on chalky rendzina on a W-, SW- and S-facing slope, by the Skierbieszów-Grabowiec road, immediately behind Wolica Uchańska (>30), $50^{\circ} 49^{\prime} 36^{\prime \prime} \mathrm{N}, 23^{\circ} 29^{\prime} 29^{\prime \prime} \mathrm{E}$, leg. A. Cwener, 27.07.2006 (LBL), vid. P. Chmielewski, 2008 [9]; Kolonia Łaziska, a degraded xer. gras. on a S- and SW-facing slope, ca. $400 \mathrm{~m} \mathrm{E}$ of the village (>20), 50 $48^{\prime} 42^{\prime \prime} \mathrm{N}, 23^{\circ} 24^{\prime} 05^{\prime \prime} \mathrm{E}$, leg. A. Cwener, 29.05.2005, vid. P. Chmielewski, 2007 [9]; Rogów, xer. gras., Inuletum ensifoliae association, in the "Rogów" res., on the calcareous slope of a water course, ca. $1 \mathrm{~km} \mathrm{SE}$ of the village (>20), 504 $47^{\prime} 52^{\prime \prime} \mathrm{N}, 23^{\circ} 31^{\prime} 28^{\prime \prime} \mathrm{E}$, leg. A. Cwener, 02.07.2006 (LBL) [9]; Żuków, degraded xer. gras. on chalky slope (>20), $50^{\circ} 47^{\prime} 51^{\prime \prime} \mathrm{N}, 23^{\circ} 28^{\prime} 09^{\prime \prime} \mathrm{E}$, leg. A. Cwener, 20.07.2006 (LBL) [9]; 55 - Maziarnia, roadsides on the margin of a forested xer. scrub complex, ca. $300 \mathrm{~m} \mathrm{~S}$ of Maziarnia n. Putnowice (>20), 5058'32" N, 2339'13" E, vid. P. Chmielewski, 25.04.2009 [9]; 71 - Gruszka Duża, a narrow belt of a xer. gras. by the roadside, ca. $1 \mathrm{~km} \mathrm{~N}$ of the village $(>15)$, $50^{\circ} 49^{\prime} 10^{\prime \prime} \mathrm{N}, 22^{\circ} 58^{\prime} 41^{\prime \prime} \mathrm{E}$, vid. P. Chmielewski, 2008 [9]; 77 - Gródek, xer. gras. on the slopes of the Bug v. stretching from the Kolonia Gródek village towards Czumów (>50), $50^{\circ} 47^{\prime} 46^{\prime \prime} \mathrm{N}, 23^{\circ} 57^{\prime} 11^{\prime \prime} \mathrm{E} ; 50^{\circ} 46^{\prime} 57^{\prime \prime} \mathrm{N}, 23^{\circ} 56^{\prime} 47^{\prime \prime} \mathrm{E}$, leg. P. Chmielewski, A. Cwener, 28.06.2008 [9]; Czumów n. Hrubieszów, loess slope on the Bug river v., leg. D. Fijałkowski, 18.07.1956, 26.07.1959 (LBL); 82 - Kąty II, initial xer. gras. near a dirt road from the Wymysłówka village to Wychody, on a midfield hill known as Wieprzecka Góra $(<20)$, $50^{\circ} 40^{\prime} 46^{\prime \prime} \mathrm{N}, 23^{\circ} 07^{\prime} 35^{\prime \prime} \mathrm{E} ; 50^{\circ} 40^{\prime} 35^{\prime \prime} \mathrm{N}, 23^{\circ} 07^{\prime} 43^{\prime \prime} \mathrm{E}$, vid. R. Piwowarczyk, W. Michalczuk, P. Chmielewski, 2006 [9]; 83 - hills n. Zamość, (as O. rapum-gensitae), leg. F. Berdau, 06.18?? (WA, 018910=28424); 85 - Kazimierówka, the side of the road from the Kotlice village towards Perespa, ca. $300 \mathrm{~m} \mathrm{~S}$ of the Kotlice Forest. Over ten specimens of O. elatior were recorded in 2007; the species was not observed afterwards although the habitat did not changed; $50^{\circ} 40^{\prime} 35^{\prime \prime} \mathrm{N}$, 2336'27" E, vid. P. Chmielewski, 2007 [9]; 94 - Sielec, Dzierążnia Kościelna, dry chalky slope, leg. M. Szozda, 16.07.1958 (LBL); 96 - Dobużek, Skarpa Dobużańska res., ca. $1 \mathrm{~km} \mathrm{NW}$ of the village, a xer. gras. belonging to ThalictroSalvietum pratensis association on the steep slope of the Huczwa river v. (>20), 50³4'50" N, 2342'56" E, leg. P. Chmielewski, R. Piwowarczyk, 14.07.2006 (KTC) [9]; GF: 04 - Tarnawatka-Tartak, fallow fields and the roadside of a field road over the hill from Tarnawatka $S$ towards the Pańków village (>20), 50³1'28" N, 2329'37" E, vid. P. Chmielewski, 27.07.2007 [9]; Huta Tarnawacka, an initial xer. gras. on the SW and S hillsides, ca. $0.5 \mathrm{~km} \mathrm{~N}$ of the village, by dirt road towards the Pauczno village $(>50)$, $50^{\circ} 32^{\prime} 05^{\prime \prime} \mathrm{N}, 23^{\circ} 29^{\prime} 37^{\prime \prime} \mathrm{E}$, vid. P. Chmielewski, 14.07.2006 [9]; 07 - Posadów, xer. gras., Thalictro-Salvietum pratensis, on chalky rendzina and chernozems, $0.5 \mathrm{~km} \mathrm{~N}$ of the village, on the edge of the Kamionka river v., on both sides of the

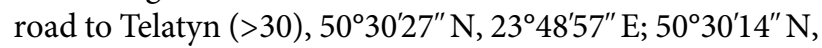
$23^{\circ} 49^{\prime} 18^{\prime \prime}$ E, vid. P. Chmielewski, 2006 [9]; 25 - Machnów n. Uhnów, steppe slope, leg. J. Motyka, 28.08.1949 (LBL); Machnowska Góra res. (Roztocze), xer. gras., leg. K.
Oklejewicz, 05.08.2009 (KRA); Machnów Stary, xer. gras. in the Machnowska Góra res., $50^{\circ} 22^{\prime} 10^{\prime \prime} \mathrm{N}, 23^{\circ} 35^{\prime} 21^{\prime \prime} \mathrm{E}$; $50^{\circ} 22^{\prime} 17^{\prime \prime} \mathrm{N}, 23^{\circ} 34^{\prime} 54^{\prime \prime} \mathrm{E}$, vid. P. Chmielewski, 2007 [9].

Localities difficult to locate in the field:

Pawłów, "Dąbrówka”, dry hill, leg. prof. Polański, 13.07.1912 (KRAM, 037793); Ostrowiec, leg. W. Gajewski, 07.1930 (WA, $018879=28398)$.

List of undifferentiated and incorrect localities:

AB: 96 - Stargard Szczeciński [111]; 97 - Ulikowo [111]; AD: 09 - Jezioro Paklicko Wielkie n. Nowy Dworek (Flußwerder im Packlitzsee) [112]; BC: 56 - Goraj n. Czarnków (Czarnikau: Goray) [113]; 78 - Oborniki [113]; 89 - Murowana Goślina (Murowanna-Goślin) [114]; BD: 08 - Poznań (Posen) [27]; 09 - Poznań Wschód (Posen-Ost) [113]; 70 - Nowe Żabno, Nowa Sól distr. [115]; BE: 84 - Lubachów (Breitenhain) [116]; CA: 87 - Kartuzy [117]; 99 - Pręgowo (Prangenau), among cereal crops n. Pręgowo [118-120]; CD: 25 - Ciążeńskie Holendry (Brzeg, unpublished data, 1995 - ATPOL); CE: 97 - Rąty (Ronty bei Karthaus), between potato cultivation and barley cultivation, specimen $61 \mathrm{~cm}$ [118]; CF: 37 - Koźle (Dajdok et al. 1998 - ATPOL]; DA: 80 - Gdańsk [117]; Westerplatte [118,121]; 87 - vicinty of Frombork, leg. Klinsmann 1844 [122]; leg. Hübner, 18?? [122], between Frombork and Stary Dwór [118]; 91 - Trutnowy [123]; DB: 73 - Szynwałd, S slope of a mountain in scrub, specimen $68 \mathrm{~cm}[118,121]$; DC: 02 - in the forest between pine trees, n. Nielubie [118]; DE: 61 - Opatów n. Kłobuck (Babczyńska-Sendek, unpublished data 1998 US); 84 - Wrzosowa, Góra Kamionka hill, gras. on slopes (Babczyńska-Sendek, unpublished data 1998 - US); DF: 02 - Babienica n. Psary, Skała, gras. (Babczyńska-Sendek, unpublished data 1998 - US); 03 - Woźniki, Coglowa Góra hill (Babczyńska-Sendek, unpublished data 1996 - US; mistaken with numerous O. lutea, not recorded by BabczyńskaSendek); 04 - Rzeniszów-Świnica (Babczyńska-Sendek, unpublished data 1998 - US; mistaken with numerous O. lutea, not recorded by Babczyńska-Sendek); 22 - Niezdara (Babczyńska-Sendek, unpublished data 1988 - US); Nakło Śląskie (Babczyńska-Sendek, unpublished data 1995 - US); 23 - Najdziszów (Babczyńska-Sendek, unpublished data 1998 - US), Goląsza Dolna (Babczyńska-Sendek, unpublished data 1997 - US); 25 - DG-Tucznawa (K. Rostański, unpublished data 1976, Jędrzejko, Żarnowiec unpublished data 1985 - all US; after misidentified specimen of O. lutea, leg. Sumara 1974, KTU); 28 - N of Sławniów n. Pilica [124]; DF: 32 - Bobrowniki, border with Kamyce (Babczyńska-Sendek, unpublished data 1998 - US; only O. lutea found in 2011); 33 - between Rogoźnik and Wojkowice (Babczyńska-Sendek, unpublished data 1993 - US), Twardowice (BabczyńskaSendek, unpublished data 1998 - US); 34 - DG, ZąbkowiceWygiełzów (Babczyńska-Sendek, unpublished data 1996 - US; 2008-2013 only present numerous O. lutea); 35 - DG, Strzemieszyce Małe [103], 44 - Sosnowiec-Sielec [Sielce bei Bendzin; (cf. [71,125] - probably both after misidentified specimen of O. lutea, leg. G. Schneider 1876, B; still present in 2010, Ł. Krajewski, unpublished)]; 46 - Trzebinia-Czyżówka, Góra Wilcza hill (Babczyńska-Sendek, unpublished data 1995 - US; only found O. lutea); 51 - Ornontowice S, n. 
Mikołów (Urbisz, unpublished data 1998 - US), 55 - Balin Duży (cf. [75,81] - mistaken with O. lutea, phot.); DG: 01 Leszna Góra, Cieszyn distr. [90]; EA: 90 - Pieniężno [118]; EB: 59 - Jezioro Mały, Piecki distr. [126]; ED: 12 - Kampinos n. Warszawa [127]; EE: 17 - Radom [127]; EF: 37 - Szczuczyn [127]; 77 - Góra St. Marcin hill, S Tarnów [128]; EG: 33 - Between Krościenko and Tylmanowa [128,129]; FG: 13 - vicinity of Iwonicz [130].

\section{Prefered habitats, plant communities and host}

Orobanche elatior and O. kochii are clearly dinstinguished by their phytoceonoses. Orobanche elatior prefers sunny hillsides and slopes of hillocks, hills and valleys but also flat areas, infrequently also the colder horizon sector, at altitudes (40)200-400(700) $\mathrm{m}$ above sea level. Its highest sites are in the Góry Orlickie Mts (Central Sudetes Mts) and the Silesian Beskid Mts (Western Carpathians). It prefers alkaline soils, usually shallow rendzinas formed on chalk marl and limestone, dolomite, loess, gypsum, and chernozem. The abundance of specimens in populations is usually small and is 5-20 shoots but sometimes only a single inflorescence is noted. The most abundant populations occur in the Sudetes Mts (one site of a few hundreds shoots) [86] and in the central part of the Silesia-Cracow Upland (a few sites with over 100 shoots). Fluctuations in the population size are noticeable at localities observed over a few vegetative seasons.

Orobanche elatior prefers a broad phytocoenotic range. It comprises intermediate communities and is often difficult to classify. This reflects the transitional and mosaic type of habitats colonized by the species and their dynamic-succession condition. Orobanche elatior occurs in xerothermic grasslands of the alliance Cirsio-Brachypodion pinnati (FestucoBrometea class) and communities of juniper scrub, e.g. in the Lublin Land. The species also often occurs in abandoned fields, fallows or wastelands, roadsides, along railways, in intermediate communities between xerothermic grasslands (Festuco-Brometea, Festucetalia valesiacae), thermophilous meadows (Molinio-Arrhenetheretea, Arrhenatheretalia), pioneer semiruderal xerothermic communities (Agropyretea intermedio-repentis) and ruderal communities (Artemisietea vulgaris, Onopordetalia, suballiance Dauco-Melilotenion, especially Dauco-Picridetum hieracioidis, and Echio-Meliloletum associations). It is fairly frequently recorded in fringe communities of the alliance Geranion sanguinei (TrifolioGeranietea class). Orobanche elatior is also encountered within or on the margins of cultivations of, e.g. rape, cereal crops, or on the margins and baulks of calcareous fields, with a contribution of species of the alliance Centauretalia cyani, e.g. Caucalidion lappulae (Stellarietea mediae class) (Appendix S1). In the Sudetes Mts, the species was noted in thermophilous grasslands on forest margins of the alliance Bromion erectii [86].

Orobanche kochii prefers sunny sites, usually gentle S or SW-facing slopes but it is also found at $\mathrm{N}$ facing or flat sites; altitude about (40)200-400(430) $\mathrm{m}$. These include xerothermic grasslands, thermophilous shrublands; located on slopes of hills, river valleys, gullies, margins of forests and fields, in former quarries, baulks, fallows and ruderal sites. It prefers alkaline soils, usually shallow rendzinas formed on chalk marl and limestone, dolomite, loess, and chernozem (black-earth soil). It is recorded most frequently in communities of the alliance Cirsio-Brachypodion pinnati (class Festuco-Brometea), especially on flowery or initial dry grasslands, i.e. Adonido-Brachypodietum pinnati, Inuletum ensifoliae, Thalictro-Salvietum pratensis, and on hills, in former gypsum excavation pits in the Nida Basin, also in Seslerio-Scorzoneretum purpureae, and in the community Carex glauca-Tetragonolobus maritimus. In the SilesiaCracow Upland it occurs mostly on strongly xerothermic fallow rendzinas and on secondary calcareous grasslands formed close to old limestone quarries, usually on steep slopes, less frequently in sligtly thermophilous north-facing associations. In the Cracow-Częstochowa Upland, the species also sometimes grows in the ecotone of rocky grasslands at foothills of limestone mogotes (Festucetum pallentis) and thermophilous scrub (Geranion sanguinei), usually in the association Origano-Brachypodietum pinnati. As a result of natural plant succession in grasslands, the communities have a high contribution or a mosaic of species of thermophilous herbaceous forest edge communities of the alliance Geranion sanguinei (class Trifolio-Geranietea sanguinei) and shrub communities, particularly of the alliance Berberidion (class Rhamno-Prunetea), as well as xeric meadow species of the alliance Arrhenatherion elatioris (class MolinioArrhenatheretea). The species is also often encountered on former fallows and wastelands, especially in rendzina soil conditions, in communities of the class Artemisietea vulgaris with a high contribution of xerothermic and meadow species (Appendix S2). The abundance of populations varies greatly and ranges from year to year. Its populations are more abundant than those of $O$. elatior and comprise 15 shoots on average, rarely app. 100-250, e.g. 100 Gartatowice, 150 (Wojkowice) and 250 (between Wojsławice and Cynków). The abundance behaviour of $O$. kochii is similar to that of $O$. picridis [14]. It rapidly and densely colonizes abandoned areas after which its number drops suddenly as a result of succession changes. However, in the central part of the Silesia-Cracow Upland, the majority of its localities are less numerous (also less numerous than O. elatior), and sometimes only single specimens could be found. At these sites the species is difficult to find (in dry forms), especially because specimens are often very sparse in other Orobanche, mostly in the much more numerous $O$. lutea. All the communities mentioned above include a high contribution of host species of C. scabiosa, with the coverage being about (5)25(50)\% (Appendix S1, Appendix S2).

\section{Discussion}

Orobanche kochii is more common and widely distributed in Poland, the Czech and Slovak Republics, and in much of Central Europe, with the distribution area shifting from central Europe towards Eastern Europe and Asia. Orobanche elatior is noticeably scarcer in Central Europe and its distribution is confined to Western and Central Europe. Their ranges overlap in Central Europe.

A revision of herbarium materials and field investigations into O. elatior and O. kochii in Poland was conducted between 1999 and 2014. Considerable differences in the 
distribution were found, especially in relation to the previous distribution map of O. elatior s.l. in Poland [70] and in Central Europe [21]. At present O. elatior occurs in Poland mainly in the Silesia-Cracow, Małopolska and Lublin Uplands, rarely in the Lower Vistula Valley, Central Sudetes Mts, Western Carpathian Mts and Carpathian Foothills. Orobanche kochii, which is definitely more common than O. elatior, has numerous localities especially in the Polish Uplands: Silesia-Cracow and Małopolska Uplands, and Lublin-Lviev, Volhynia Uplands, Roztocze and Polesie (Fig. 3, Fig. 4). Our research demonstrated that O. kochii and $O$. lutea are the most common representatives of this genus in Poland.

The abundance of populations of O. elatior and O. kochii varies greatly by region in Poland and fluctuates considerably in individual years. The both taxa are monophagous species and in Poland, like in other countries of Central Europe, they are parasitic on C. scabiosa.

Zázvorka [21] stated that O. kochii and O. elatior had never been found growing together at the same site, but they sometimes occur together in Poland (e.g. DG-Błędów, DG-Łosy, DG-Gołonóg, Podskale, Jaworzno-Ciężkowice, Lędziny, Imielin/Mysłowice).

The new form described as O. kochii f. citrina, and found in the populations of typical individuals, within the same habitat conditions, was previously known from Poland only, but may possibly be identified in a wider geographical range. We still need to confirm the cream color forms described as O. kochii and presented in photographs taken in the Crimea (Tepe-Oba Mts near Teodosia and Mys Fiolent), without any certain information on a host plant (http://www.plantarium. $\mathrm{ru})$. However, herbarium materials at LE from the Crimea (Mys Fiolent) include individuals of O. ritro, parasitizing Echinops ritro [20], with a characteristic creamy or less common yellow color of corolla [27,62]. Many species of the genus Orobanche, e.g. O. alba, O. alsatica s.l., O. caryophyllacea, O. hederae, O. laxissima group, are often lighter in color than the typical, commonly occur form, but these forms almost never constitute the majority of a population. Such pigmentation is not typical and sometimes may also result from low insolation, soil $\mathrm{pH}$, hosts, or incomplete plant pigmentation. Yellow and albinotic forms usually occur in shaded sites [10-12,68,131-133], but sometimes also in places exposed to strong sunlight.

The role of seed features in the identification of species Orobanche to relate such characters to the systematics of the group, have been presented in several studies (e.g. $[11,40,68,132,134,135])$. The use of micromorphological characters, i.e. seed and pollen ornamentation (SEM) or a cross-section of the exine of dust seeds (TEM), have revealed additional differences between related species of O. alsatica agg. (O. alsatica, O. bartlingii, O. mayeri) [132]. Concerning the seeds of the investigated species, the best taxonomic character is the diameter and the shape of wall perforations. In O. elatior the perforation diameter is much larger, $4-13 \mu \mathrm{m}$, and is usually elliptical, while in $O$. kochii the diameter is smaller, $2-4 \mu \mathrm{m}$, and subcircular. The size and shape of seeds is less important for species identification. The position of a very large number of seeds in the ovary may also determine their shape as well as that of their cells $[19,136]$. Palynological analysis also revealed auxiliary micromorphological subtle differences in the size and level of sculpture of pollen grains between both species [137]. Differences in morphology, preliminary molecular studies, seed and pollen sculpture, and some ecological preferences confirm the separation of the examined taxa at species level.

Orobanche elatior s.l. is a partially protected species in Poland (regulation 2014). It is not a common species and is included on the "Red list of vascular plants in Poland" as rare - R [138] and vulnerable (VU) in the Carpathian Mts [79]. It is also included on regional red lists and books: Gdańsk Pomerania, CR, Western Pomerania, E [139,140]; Western Pomerania and Wielkopolska, E [139]; Wielkopolska, CR [141]; Sudetes Mts, CR [142]; Opole province, CR [56], endangered, EN, in the Lower Silesia province [143], Kujawy-Pomerania region, I (indeterminate) [144], Małopolska Upland, VU [145]. The species is also vulnerable in neighboring countries, i.e. Germany [146,147], the Czech Republic [148] and Slovakia [149]. These threat categories require revision as they concern O. elatior s.l., which contained the rare $O$. elatior and considerably more common O. kochii. Both species are included together only in the vascular plant red list of the Silesia province (O. elatior - category VU, vulnerable and O. kochii - NT, near threatened) [150], coauthored by us.

The progressing process of secondary succession of treeand shrub vegetation, the density of the herb layer and the cessation of former cultivation methods, especially the loss of grazing, are the main threats to both species. Their sites are often found near arable fields where they are exposed to chemical agents. Orobanche elatior is especially vulnerable as it often prefers habitats in the ecotone of arable fields, and tetralogic and deformed forms affected by weed-killing agents are often observed. Similarly due to the impact of EU subsidies on cultivation profitability, O. kochii localities on old fallows are reploughed. Land development is a direct threat in many cases as the species' habitats are often in scenic landscapes that are demanded for housing estates, especially in the central part of the Silesia-Cracow Upland, where numerous localities of both $O$. kochii and O. elatior are now on the margin of one of the largest European conurbations. Some localities are on the edge of operating, expanding quarries. A part of the population of O. kochii on the dolomite quarry in the DG-Ząbkowice has disappeared in this way. The arrival of invasive or expansive species also poses a considerable threat. Heracleum sosnowskyi has been moving worryingly close to its population. Mass self-sowing of Solidago canadensis, S. gigantea and Calamagrostis epigejos is observed at many sites. Only a few localities are protected: O. elatior - Bielinek res. (not confirmed here for many years), Gipsowa Góra hill, Machnowska Góra hill, Polana Polichno; O. kochii - Zimne Wody, Żmudź, Murawy Dobromierskie, Biała Góra hill, Skarpa Dobużańska, Rogów, Opalonki, Przęślin, Skorocice, Krzyżanowice, Skotniki Górne; also protected as ecological sites or within Natura 2000 sites. This does not ensure the preservation of the species as active protection is needed. Many localities are at disturbed sites or at operating excavation sites (limestone, gypsum). At least some of the localities should be protected as ecological sites and active protection measures should be implemented: 
mowing or grazing of excessively developing field- and herbaceous vegetation, while preserving the unique mosaic systems and fringe communities, and nature monitoring. The abundance of the host species C. scabiosa should also be monitored as this is usually neglected or overlooked in the protection of parasitic plants. Special attention should be paid to the sites were $O$. kochii and $O$. elatior co-occur

\section{Acknowledgments}

The author thanks the curators of herbaria and other persons who kindly made their data on the species available. We are also grateful for the assistance during field studies. Special thanks are due to Jiri Zázvorka for invaluable comments and discussion and to Beata Babczyńska-Sendek for our field excursions and for providing access to the University of Silesia Orobanche database. This work was supported by the Polish Ministry of Science [grant No. NN303357733 (2008-2009), NN303551939 (2010-2013)] and partially Principal Research Project 612419 (2014-2015).

\section{Authors' contributions}

The following declarations about authors' contributions to the research have been made: concept of the study: RP; herbarium revision: RP; micromorphology of seeds, taxonomy and phytosociological analysis: RP; writing the manuscript and field research: RP, $Ł K$.

\section{Competing interests}

No competing interests have been declared.

\section{Supplementary material}

The following supplementary material for this article is available online at http://pbsociety.org.pl/journals/index.php/asbp/rt/suppFiles/ asbp.2014.031/0:

1. Appendix S1: plant communities with Orobanche elatior in Poland.

2. Appendix S2: plant communities with Orobanche kochii in Poland.

\section{References}

1. Uhlich H, Pusch J, Barthel KJ. Die Sommerwurzarten Europa: Gattung Orobanche. Magdeburg: Westarp-Wiss.; 1995.

2. Pusch J, Günther KF. Orobanchaceae (Sommerwurzgewächse). In: Hegi G, editor. Illustrierte Flora von Mitteleuropa. Lieferung 1. Jena: Weissdorn-Verlag; 2009. p. 1-99. (vol 6/1A).

3. Joel DM, Gressel J, Musselman LJ (eds.). Parasitic Orobanchaceae: parasitic mechanisms and control strategies. Springer: Heidelberg; 2013.

4. Zázvorka J. Orobanchaceae Vent. Zárazovité. In: Goliášová K, editor. Flóra Slovenska. Bratislava: VEDA; 1997. p. 460-529. [vol 5(2)].

5. Zázvorka J. Orobanchaceae - zarazovite. In: Slavik B, editor. Kvetena Česke Republiky. Praha: Academia; 2000. p. 477-513. (vol 6).

6. Piwowarczyk R, Przemyski A. New locality of Orobanche coerulescens Stephan ex Willd. (Orobanchaceae) at the NW limit of its geographical range. Acta Soc Bot Pol. 2009;78(4):291-295. http:// dx.doi.org/10.5586/asbp.2009.038

7. Piwowarczyk R, Przemyski A. The distribution and habitat preferences of the declining species Orobanche arenaria (Orobanchaceae) at the northern limit of its geographical range. Acta Soc Bot Pol. 2010;79(1):43-50. http://dx.doi.org/10.5586/asbp.2010.007

8. Piwowarczyk R, Chmielewski P, Gierczyk B, Piwowarski B, Stachyra P. Orobanche pallidiflora Wimm. \& Grab. in Poland: distribution, habitat and host preferences. Acta Soc Bot Pol. 2010; 79(3):197-205. http://dx.doi.org/10.5586/asbp.2010.025

9. Piwowarczyk R, Chmielewski P, Cwener A. The distribution and habitat requirements of the genus Orobanche L. (Orobanchaceae) in SE Poland. Acta Soc Bot Pol. 2011;80(1):37-48. http://dx.doi. org/10.5586/asbp.2011.006

10. Piwowarczyk R. Orobanche mayeri (Suess. \& Ronniger) Bertsch \& F. or have been recorded for a very long time (Góra Gipsowa Mt 1841-2010, Góra Tuł hill 1858-2008, between Pasieczki and Dziećkowice 1863-2010), or localities usually indicating exceptionally well-preserved patches of xerothermic grasslands, including other rare Orobanche species (O. lutea, O. bartlingii, O. picridis, O. caryophyllacea, O. alsatica).

Bertsch - the new species to Poland. Acta Soc Bot Pol. 2011;80(3):179_ 183. http://dx.doi.org/10.5586/asbp. 2011.020

11. Piwowarczyk R. Orobanche alba subsp. alba and subsp. major (Orobanchaceae) in Poland: current distribution, taxonomy, plant communities, hosts, and seed micromorphology. Biodiv Res Conserv. 2012;26:23-38. http://dx.doi.org/10.2478/v10119-012-0005-6

12. Piwowarczyk R. Revised distribution and plant communities of Orobanche alsatica and notes on the Orobanchaceae series Alsaticae in Poland. Biodiv Res Conserv. 2012;26:39-51. http://dx.doi.org/10.2478/ v10119-012-0008-3

13. Piwowarczyk R. The genus Orobanche L. (Orobanchaceae) in the Małopolska Upland (S Poland): distribution, habitat, host preferences and taxonomic problems. Biodiv Res Conserv. 2012;26:3-22. http:// dx.doi.org/10.2478/v10119-012-0009-2

14. Piwowarczyk R. A revision of distribution and the ecological description of Orobanche picridis (Orobanchaceae) at the NE limit of its geographical range from Poland and Ukraine. Acta Agrobot. 2012;65(1):91-106. http://dx.doi.org/10.5586/aa.2012.047

15. Piwowarczyk R. Orobanche bohemica Čelak. (Orobanchaceae) at the eastern limit of its geographical range: new data on its distribution in Poland. Biodiv Res Conserv. 2012;26:53-59. http://dx.doi.org/10.2478/ v10119-012-0001-x

16. Piwowarczyk R. Revised distribution and phytosociological data of Orobanche coerulescens Stephan in Willd. (Orobanchaceae): Poland in relation to Central Europe. Biodiv Res Conserv. 2012;26:61-72. http://dx.doi.org/10.2478/v10119-012-0007-4

17. Piwowarczyk R. Orobanche purpurea (Orobanchaceae) in Poland: current distribution, taxonomy, plant communities, and preferred hosts. Biodiv Res Conserv. 2012;26:73-81. http://dx.doi.org/10.2478/ v10119-012-0006-5

18. Piwowarczyk R. A revision of distribution and historical analysis of preferred hosts of Orobanche ramosa (Orobanchaceae) in Poland. Acta Agrobot. 2012;65(1):53-62. http://dx.doi.org/10.5586/aa.2012.043

19. Piwowarczyk R. Seed productivity in relation to other shoot features for endangered parasitic plant Orobanche picridis F.W. Schultz (Orobanchaceae). Pol J Ecol. 2013;61(1):55-64.

20. Nobis M, Nowak A, Nobis A, Paszko B, Piwowarczyk R, Nowak S, et al. Contribution to the flora of Asian and European countries: new national and regional vascular plants records. Acta Bot Gal. 2014;160(1):81-89. http://dx.doi.org/10.1080/12538078.2013.871209

21. Zázvorka J. Orobanche kochii and O. elatior (Orobanchaceae) in central Europe. Acta Musei Moraviae, Scientiae biologicae (Brno). 2010;95(2):77-119.

22. Hess HE, Landolt E, Hirzelr R. Flora der Schweiz. Stuttgart: Birkhäuser Verlag, Basel; 1972. (vol 3).

23. Frajman B, Krajšek SS, Dakskobler I. Orobanche kochii F. W. Schultz and Orobanche elatior Sutton (Orobanchaceae) - new species for the flora of Slovenia. Hladnikia. 2011;27:57-65.

24. Meusel H, Jäger E, Rauschert S, Weinert E. Vergleichende Chorologie der Zentraleuropäischen Flora. Jena: Gustav Fischer Verlag; 1978. (vol 2).

25. Hultén E, Fries M. Atlas of North European vascular plants north of the tropic of cancer. Königstein: Koeltz Scientific Books; 1986. (vol 1-3).

26. Beck G. Monographie der Gattung Orobanche. Bibl. Bot. 19, Cassel: Theodor Fischer; 1890. 
27. Beck G. Orobanchaceae. In: Engler A, editor. Das Pflanzenreich IV. (261). Leipzig: Verlag von Wilhelm Engelmann; 1930. p. 1-348.

28. Novopokrovskij IV, Tzvelev NN. Sem. CXLVI. Zarazichovye Orobachaceae Lindl. In: Flora SSSR. Moskva \& Leningrad: Izdatel'stvo Akademii Nauk SSSR; 1958. p. 685-687. (vol 23).

29. Tzvelev NN. Sem. 146. Orobanchaceae Vent. - zarazichovye. In: Flora evropejskoj chasti SSSR. Leningrad: Nauka; 1981. p. 317-336. (vol 5).

30. Zhiyun Z, Tzvelev NN. Orobanchaceae. In: Zheng-Yi W, Raven PH, editors. Flora of China. Saint Louis, MO: Science Press, Beijing, and Missouri Botanical Garden Press; 1998. p. 229-243. (vol 18).

31. Mirek Z, Musiał L, Wójcicki JJ. Polish herbaria. Polish Bot Stud Guideb. 1997;18:1-110.

32. Thiers B. Index Herbariorum: a global directory of public herbaria and associated staff. New York Botanical Garden's Virtual Herbarium [Internet]. 2014 [cited 2014 Feb 20]; Available from: http://sciweb. nybg.org/science2/IndexHerbariorum.asp

33. Braun-Blanquet J. Pflanzensoziologie, Grundzüge der Vegetationskunde. Vienna: Springer Verlag; 1964. (vol. 3).

34. Mirek Z, Piękoś-Mirkowa H, Zając A, Zając M. Flowering plants and pteridophytes of Poland - a checklist. In: Mirek Z, editor. Biodiversity of Poland. Kraków: W. Szafer Institute of Botany, Polish Academy of Sciences; 2002. (Biodiversity of Poland; vol 1).

35. Matuszkiewicz W. Przewodnik do oznaczania zbiorowisk roślinnych Polski. Vademecum Geobotanicum. Warszawa: Wydawnictwo Naukowe PWN; 2006

36. Zając A. Założenia metodyczne "Atlasu rozmieszczenia roślin naczyniowych w Polsce”. Wiad Bot. 1978;22(3):145-155.

37. Barthlott W. Epidermal and seed surface characters of plants: systematic applicability and some evolutionary aspects. Nord J Bot. 1981;1:345-355. http://dx.doi.org/10.1111/j.1756-1051.1981.tb00704.x

38. Barthlott W. Microstructural features of seed surfaces. In: Heywood VH, Moree DM, editors. Current concepts in plant taxonomy. London: Academic Press; 1984. p. 95-105.

39. Stearn WT. Botanical Latin. London: David \& Charles; 1992.

40. Plaza L, Fernández I, Juan R, Pastor J, Pujadas A. Micromorphological studies on seeds of Orobanche species from the Iberian Peninsula and the Balearic Islands, and their systematic significance. Ann Bot. 2004;94:167-178. http://dx.doi.org/10.1093/aob/mch124

41. Bojnansky V, Fargasová A. Atlas of seeds and fruits of Central and East-European flora. The Carpathian Mountains region. Dordrecht: Springer; 2007.

42. Black M, Bewley JD, Halmer P. The encyclopedia of seeds, science, technology and uses. Wallingford: CAB International; 2008.

43. Łomnicki A. Wprowadzenie do statystyki dla przyrodników. Warszawa: Wydawnictwo Naukowe PWN; 2000

44. Sutton C. A description of five species of Orobanche. Trans Linn Soc Lond. 1798;4:173-181. http://dx.doi.org/10.1111/j.1096-3642.1798. tb00525.x

45. Wimmer F. Flora von Schlesien preussischen und österreichischen Anteils. Breslau: Verlag von Ferdinand Hirt; 1841.

46. Holandre JJJ. Nouvelle Flore de la Moselle. 2 ed. 1842. (vol 2).

47. Schultz F. Orobanche kochii, eine neue deutsche Art. Flora. 1847;30(5):65-67.

48. Turland N, Rumsey F. Proposals to reject the names Orobanche major and O. laevis (Orobanchacaea). Taxon. 1997;46:787-791. http://dx.doi. org/10.2307/1224494

49. Foley MJY. Orobanche L. In: Paiva J, Sales F, Hedge IC, Aedo C, Aldasoro JJ, Castroviejo S, et al., editors. Flora Iberica. Madrid: Real Jardín Botánico; 2001. p. 32-72. (vol 14).

50. Halacsy E, Braun H. Nachträge zur Flora von Nieder-Österreich, Wien: in Komm. W. Braumüller; 1882.

51. Beck G. Orobancheae novae. Feddes Repert. 1922;30(1):33-40.

52. Maly J. Die Orobanchen der Grätzer Legend. Flora. 1842;1:113-127.
53. Čelakowský L. Prodromus der Flora von Böhmen. Prague: Arch. Naturwiss. Landesdurchforsch. Böhm.; 1871. (vol 2).

54. Fiek E. Flora von Schlesien preussischen und österreichischen Antheils, enhaltend die wildwachsenden, verwilderten und angebauten Phanerogamen und Gefäss-Cryptogamen. Breslau: J.U. Kern’s Verlag; 1881.

55. Schube T. Verbreitung der gefässpflanzen in Schlesien preussischen und österreichischen Anteils. Breslau: R. Nischowsky; 1903.

56. Nowak A, Nowak S. Zaraza wielka, Orobanche elatior Sutton. In Nowak A, Spałek K, editors. Czerwona księga roślin województwa opolskiego. Rośliny naczyniowe wymarłe, zagrożone i rzadkie. Opole: OTPN; 2002. p. 141.

57. Teryokhin ES, Schibakova GV, Serafimovich NB, Kravcova TI. Opredelitel' zarazichovych flory SSSR (s atlasom plodov i semjan). Determinator of broomrapes of the USSR flora (with atlas of fruits and seeds). Sankt-Peterburg: Nauka; 1993.

58. Frajman B, Carlón L, Kosachev P, Sánchez Pedraja O, Schneeweiss GM Schönswetter P. Phylogenetic position and taxonomy of the enigmatic Orobanche krylowii (Orobanchaceae), a predominatly Asian species newly found in Albania (SE Europe). Phytotaxa. 2013;137(1):1-14. http://dx.doi.org/10.11646/phytotaxa.137.1.1

59. Grenier JCM, Godron DA. Flore de France 2. Paris: J.B. Baillière; 1853.

60. Chater AO, Webb DA. Orobanche. In: Tutin TG, Heywood VH Burges NA, Moore DM, Valentine DH, Walters SM, et al., editors. Flora Europaea 3, Cambridge: Cambridge University Press; 1972.

61. Pignatti S. Flora d'Italia 2. Bologna: Edagricole; 1982.

62. Pujadas-Salvà AJ. Typification and characterization of Orobanche ritro Gren. \& Godr. (Orobanchaceae) of Central and Southern Europe. Acta Bot Gal. 2012;159(1):67-72. http://dx.doi.org/10.1080/12538 078.2012 .671644

63. Carlón L, Laínz M, Moreno Moral G, Sánchez Pedraja Ó. A new species (Orobanche loscosii), a prioritary name for O. icterica (O. leptantha) and a new member of the Spanish flora (O. elatior). Flora Montiberica. 2011;48:89-101.

64. Pujadas-Salvà AJ. Orobanche icterica Pau y Orobanche ritro Gren. \& Godr. (Orobanchaceae) en la Flora Ibérica. Acta Botanica Malacitiana. 2013;38:160-162.

65. Pujadas-Salvá AJ, Plaza-Arregui L, Triano-Muñoz E, Algarra-Ávila JA. Orobanche icterica (Orobanchaceae) revisited. Bot J Linn Soc. 2005;148:117-124. http://dx.doi.org/10.1111/j.1095-8339.2005.00391.x

66. Rumsey FJ, Jury SL. An account of Orobanche L. in Britain and Ireland. Watsonia. 1991;8:257-295.

67. Rumsey FJ. A reconsideration of Orobanche maritima Pugsley (Orobanchaceae) and related taxa in southern England and the Channel Islands. Watsonia. 2007;26:473-476.

68. Halamski AT, Piwowarczyk R. Graines d'Orobanches comme critère taxonomique: information sur les travaux en cours (Résumé de la communication du 9 mai 2007). Bull Mens Soc Linn Lyon. 2008;77(3-4):37-40

69. Schneeweiss GM. Correlated evolution of life history and host range in the nonphotosynthetic parasitic flowering plants Orobanche and Phelipanche (Orobanchaceae). J Evol Biol. 2006;20(2):471-478. http:// dx.doi.org/10.1111/j.1420-9101.2006.01273.x

70. Zając A, Zając M, editors. Atlas rozmieszczenia roślin naczyniowych w Polsce. Nakładem Pracowni Chorologii Komputerowej Instytutu Botaniki Uniwersytetu Jagiellońskiego, Kraków; 2001.

71. Uechtritz R. Resultate der Durchforschung der schlesischen Phanerogammenflora im Jahre 1878. Jahres-Bericht Schles Ges vater Cult., Breslau. 1879;56:154-176.

72. Kotula B. Spis roślin naczyniowych z okolicy Przemyśla. Spraw Komisji Fizjogr AU. 1881;15:1-90.

73. Fijałkowski D. Flora roślin naczyniowych Lubelszczyzny. Lublin: Lubelskie Towarzystwo Naukowe; 1994.

74. Kucharczyk M. Distribution atlas of vascular plants in the Middle Vistula River Valley. Lublin: UMCS Press; 2001 
75. Urbisz A. Konspekt flory roślin naczyniowych Wyżyny KrakowskoCzęstochowskiej, Prace Naukowe Uniwersytetu Śląskiego. Katowice: Wydawnictwo Uniwersytetu Śląskiego; 2004.

76. Urbisz A. Atlas rozmieszczenia roślin naczyniowych na Wyżynie Krakowsko-Częstochowskiej. Katowice: Centrum Dziedzictwa Przyrody Górnego Śląska; 2012.

77. Babczyńska-Sendek B. Problemy fitogeograficzne i syntaksonomiczne kserotermów Wyżyny Śląskiej. Prace Naukowe Uniwersytetu Śląskiego, Katowice; 2005.

78. Piękoś-Mirkowa H, Mirek Z. Flora Polski. Rośliny chronione. Warszawa: Multico Oficyna Wydawnicza; 2006.

79. Bartoszek W, Piwowarczyk R. Zaraza wielka. Orobanche elatior Sutton. In: Mirek Z, Piękoś-Mirkowa H, editors. Czerwona księga Karpat polskich. Rośliny naczyniowe. Kraków: Instytut Botaniki im.W. Szafera PAN i Instytut Ochrony Przyrody PAN; 2008.

80. Nowak-Dańda A, Dańda P. Nowe stanowisko Orobanche elatior (Orobanchaceae) na Wyżynie Krakowsko-Częstochowskiej. Fragm Flor Geobot Pol. 2008;15(1):137-139.

81. Dubiel E, Gawroński S, Grzegorzek P. Atlas roślin chronionych, rzadkich i ginących gminy Chrzanów. Chrzanów: Urząd Miejski; 2000.

82. Schulz R. Eine floristische und geologische Betrachtung des märkischen unteren Odertales. Verh Bot Ver Prov Brandenburg. 1916;58:76-105.

83. Schulz R. Zweiter Beitrag zur Flora des märkischen unteren Odertales. Bot Ver Prov Brandenburg. 1919;61:82-96.

84. Celiński F, Filipek M. Flora i zespoły roślinne leśnostepowego rezerwatu w Bielinku nad Odrą. Badania fizjograficzne nad Polską Zachodnią. 1958;4:5-198.

85. Rätzel S, Zimmermann F. Verbreitung der Arten der Gattung Orobanche L. in Brandenburg und Berlin. Verh Bot Ver Berlin Brandenburg. 1999;132:19-101.

86. Smoczyk M. Rzadkie i zagrożone rośliny naczyniowe polskiej części Pogórza Orlickiego (Sudety Środkowe) - część 2. Przyr Sudetów. 2012;15:3-16.

87. Gołąb Z. Inwentaryzacja stanowisk chronionych, rzadkich zagrożonych gatunków roślin i grzybów na terenie gminy Lewin Kłodzki [manuscript]. In: Jankowski W, editor. Inwentaryzacja botaniczna gminy Lewin Kłodzki. Wrocław: "Fulica” Jankowski Wojciech na zlecenie Wojewódzkiego Konserwatora Przyrody we Wrocławiu; 2002.

88. Smoczyk M, Jakubska A. Rozmieszczenie storczykowatych Orchidaceae w polskiej części Gór Orlickich i Pogórza Orlickiego. Przyr Sudetów. 2004;7:41-54.

89. Smoczyk M. Rzadkie i zagrożone rośliny naczyniowe Pogórza Orlickiego (Sudety Środkowe) - część 1. Przyr Sudetów. 2010;13:53-70.

90. Schube T. Ergebnisse der Durchforschung der schlesischen Gefässpflanzenwelt im Jahre 1904. Jahres-Bericht Schles Ges vater Cult, Breslau. 1905;82:41-64.

91. Wimmer F. Flora von Schlesien. Breslau: Ferdinand Hirt; 1869.

92. Gierczyk B, Soboń J. Nowe stanowiska chronionych, zagrożonych rzadko spotykanych gatunków roślin naczyniowych w Polsce. Przegl Przyr. 2008;19:3(4):19-31.

93. Schube T. Ergebnisse der Durchforschung der schlesischen Gefässpflanzenwelt im Jahre 1910. Jahres-Bericht Schles Ges vater Cult, Breslau. 1911;88:88-105.

94. Kolbenheyer C. Vorarbeiten zur Flora von Teschen und Bielitz. Ver zool-bot Ges in Wien. 1862;12:1185-1220.

95. Oborny A. Flora von Mähren und österr. Schlesien enthaltend die wildwachsenden, verwilderten und häufi gangebauten Gefässpflanzen. Brünn: C. Winiker; 1885.

96. Formánek E. Kvetena Moravy a rakouského Slezka. Brno: E. Formánek; 1887.

97. Pelc S. Rośliny naczyniowe Pogórza Cieszyńskiego. Rocz Nauk Dydak WSP Krak. 1967;28:109-208.

98. Pacyna A. Rośliny naczyniowe wschodniej części Pogórza Wielickiego i przylegajacej części Beskidów (Karpaty Zachodnie). Prace Bot. 2004;38:1-367.

99. Jakubowska-Gabara J, Kucharski L, Zielińska K, Kołodziejek J, Witosławski P, Popkiewicz P. Atlas rozmieszczenia roślin naczyniowych w Polsce Środkowej. Gatunki chronione, rzadkie i narażone. Łódź: Wydawnictwo UŁ; 2011

100. Karo F. Flora okolic Częstochowy. Pam Fizjogr. 1881;1:208-257.

101. Hereźniak J. Stosunki geobotaniczno-leśne północnej części Wyżyny Śląsko-Krakowskiej na tle zróżnicowania i przemian środowiska. Mon Bot. 1993;75:1-368. http://dx.doi.org/10.5586/mb.1993.001

102. Babczyńska-Sendek B, Błońska A, Hejdysz J. Characteristics of the flora of fallow lands on rendzina soils on the Twardowice Plateau (Silesian Upland). Acta Agrobot. 2012;65(4):75-90. http://dx.doi. org/10.5586/aa.2012.024

103. Sendek A. Rośliny naczyniowe Górnośląskiego Okregu Przemysłowego. Warszawa: OTPN, PWN; 1984

104. Celiński F, Rostański K, Sendek A, Wika S, Cabała S. Nowe stanowiska rzadkich roślin naczyniowych na Górnym Śląsku i terenach przyległych. Cz. IV. Opolskie Tow Przyj Nauk Zesz Przyr. 1978/1979;18:3-18.

105. Uechtritz R. Zur Flora Schlesiens. Öst Bot Z XIII. 1863;4:116-119. http://dx.doi.org/10.1007/BF01816675

106. Fiek E. Ergebnisse der Durchforschung der schlesischer Phanerogamenflora im Jahre 1891. Jahr-Ber Schles Ges vaterl Kultur. 1892;69:155-180.

107. Nobis M, Nobis A. Nowe dane dotyczące występowania storczyka purpurowego Orchis purpurea Huds. (Orchidaceae) na Wyżynie Małopolskiej. Chrońmy Przyr Ojcz. 2010;66(2):149-155.

108. Nobis M. Rośliny naczyniowe zachodniej części Przedgórza Iłżeckiego (Wyżyna Małopolska). Prace Bot. 2007; 40:1-458

109. Piwowarczyk R. Rośliny naczyniowe wschodniej części Przedgórza Iłżeckiego (Wyżyna Małopolska). Prace Bot. 2010;43:1-344

110. Kalinowski P. Rzadkie rośliny naczyniowe Podlasia Nadbużańskiego cz. 1. Gatunki siedlisk murawowych, łąkowych i szuwarowych. Fragm Flor Geobot Pol. 2012;19(2):361-377.

111. Schmidt WLE. Flora von Pommern und Rügen. 1. Aufl. 1840. In der Becker und Altendorff'schen Buchhandlung, Stettin; 2. Aufl . 1848. Vermehrt und verbessert von Dr. Baumgardt. Stettin: Verlag von Ferdinand Müller; 1848

112. Decker P. Beiträge zur Flora der südlichen Neumark und der östlichen Niederlausitz. Verh Bot Ver Provinz Brandenburg. 1911;53:87-269.

113. Ascherson P, Graebner P. Flora des nordostdeutschen Flachlandes (ausser Ostpreussen). Berlin: Verlag von Gebrüder Borntraeger; 1898/99.

114. Ritschl G. Flora des Grossherzogthums Posen. Berlin; 1850.

115. Schube T. Ergebnisse der Durchforschung der schlesischen Gefässpflanzenwelt im Jahre 1928. Jahres-Bericht Schles Ges vater Cult, Breslau. 1929;101:88-96.

116. Schube T. Die Ergebnisse der Durchforschung der schlesischen Gefässpflanzenwelt im Jahre 1908. Jahres-Bericht der Schles Gesellsch vaterl Cultur. 1909;86:48-67.

117. Scholz JB. Die Pflanzengenossenscheften Westpreussens. Schriften der naturforschenden gesellschaft in danzig. Danzig: Kommissions Verlag von Wilhelm Engelman in Leipzig; 1905

118. Abromeit J, Neuhoff W, Steffen H. Flora von Ost- und Westpreussen 1898-1940, 1/1-25 (1898): 1-402, 2/26-43 (1903): 403-684, 3/44-49 (1926): 685-780. Berlin: Kommissionsverlag Gräfe und Unzer; 1940.

119. Klinsmann EF. Beiträge zur Flora von Danzig nebst einigen Mittheilungen aus andern Preußischen Gegenden in Preussische ProvinzialBlätter. Königsberg: D.W.L. Richter; 1836. (vol 15).

120. Wiess G. Die um Danzig wildwachsenden Pflanzen nach ihrem Geschlechtstheilen geordnet und beschrieben von Gottfried Reyger. Danzig: Anhuthsche Buchhandlung; 1825.

121. Preuss H. Die pontischen Pflanzenbestände im Weichselgebiet vom sandpunkt der Naturdenkmalpflege aus geschildert. Beiträge zur Naturdenkmalpflege. 1912;2:350-540. 
122. Mądalski J. Atlas flory polskiej i ziem ościennych (Florae Polonica terrarumque adiacentium iconographia), Scrophulariaceae (Pars 4), Orobanchaceae, 17(1), Warszawa: Państwowe Wydawnictwo Naukowe PWN; 1973.

123. Preuss H. Das Herbarium Klinsmann unter besonderer Berücksichtigung der Danziger Adventivflora. Ber Westpreuss Bot-Zool Ver. 1928;50:201-230.

124. Babczyńska-Sendek B, Kloczkowska A, Błońska A. Xerothermic grasslands of Pilica surroundings - diversity, threats and directions of changes. Biodivers Res Conserv. 2011;23(1):59-70. http://dx.doi. org/10.2478/v10119-011-0019-5

125. Raciborski M. Zmiany zaszłe we florze okolic Krakowa w ciągu ostatnich lat dwudziestu pięciu pod względem roślin dziko rosnących. Sprawozdania Komisji Fizjograficznej. 1884;18:99-126.

126. Polakowski B. Zespoły łąkowo-pastwiskowe Pojezierza Mazurskiego w świetle dotychczasowych badań. Zesz Nauk ART Olsztyn. 1979;28:113-121.

127. Rostafiński J. Florae Polonicae Prodromus, Uebersicht der bis jetzt im Königreiche Polen beobachteten. Phanerogamen. Verh Zool-Bot Ges. 1872; 81-202.

128. Knapp JA. Die bisher bekannten Pflanzen Galiziens und der Bukowina. Wien: Braumüller Verl.; 1872. http://dx.doi.org/10.5962/bhl.title.9730

129. Herbich F. Botanischer Ausflug in die galizisch-karpatischen Alpen des Sandezer Kreises. Flora. 1834;17:561-587.

130. Knapp JA. Przyczynek do flory obwodów jasielskiego i sanockiego. Spraw Kom Fizjogr CK Tow Nauk Krak. 1869;3:74-109.

131. Halamski AT. Orobanche hederae Vaucher ex Duby (Orobanchaceae) - plasticité phénotypique et micro-morphologie des graines. Bull Mens Soc Linn Lyon. 2011;80(7-8):170-178.

132. Piwowarczyk R, Halamski AT, Durska E. Seed and pollen morphology in the Orobanche alsatica complex (Orobanchaceae) from central Europe and its taxonomic significance. Aust Syst Bot. 2014; 27(2):145-157. http://dx.doi.org/10.1071/SB14013

133. Piwowarczyk R, Tatanov I. Orobanche laxissima Uhlich \& Rätzel (Orobanchaceae) - a new species for Dagestan (Russia) and Azerbaijan. Biodivers Res Conserv. 2013;32:25-28.

134. Musselman LJ, Mann WF. A survey of surface characteristics of seeds of Scrophulariaceae and Orobanchaceae using scanning electron microscopy. Phytomorphology. 1976;26:370-378.

135. Abu Sbaih HA, Jury SL. Seed micromorphology and taxonomy in Orobanche (Orobanchaceae). Flora Mediterranea. 1994;4:41-48.

136. Piwowarczyk R, Jankowska-Blaszczuk M. Intra-specific diversity of seed productivity and morphological features in parasitic species Orobanche bartlingii Griseb. (Orobanchaceae). Pol J Ecol. 2014;62;723-738.

137. Piwowarczyk R, Madeja J, Nobis M. Pollen morphology of the Central European broomrapes (Orobanchaceae: Orobanche, Phelipanche and Orobanchella) and its taxonomical implications. Plant Syst Evol. 2015;301;795-808. http://dx.doi.org/10.1007/s00606-014-1117-6

138. Zarzycki K, Szeląg Z. Red list of the vascular plants in Poland. In: Mirek Z, Zarzycki K, Wojewoda W, Szeląg Z., editors. Red list of plants and fungi in Poland. Kraków: W. Szafer Institute of Botany, Polish Academy of Sciences; 2006.

139. Żukowski W, Jackowiak B. List of endangered and threatened vascular plants in Western Pomerania and Wielkopolska (Great Poland). In: Żukowski W, Jackowiak B, editors. Endangered and threatened vascular plants of Western Pomerania and Wielkopolska. Poznań: Publications of the Departament of Plant Taxonomy of Adam Mickiewicz University in Poznań; 1995. (vol 3).

140. Markowski R, Buliński M. Ginące i zagrożone rośliny naczyniowe Pomorza Gdańskiego. Acta Bot Cassub Monogr. 2004;1:1-75.

141. Jackowiak B, Celka Z, Chmiel J, Latowski K, Żukowski W. Red list of vascular flora of Wielkopolska (Poland). Biodivers Res Conserv. 2007;15:95-127.

142. Fabiszewski J, Kwiatkowski P. Threatened vascular plants of the Sudeten Mountains. Acta Soc Bot Pol. 2002;71(4):339-350. http:// dx.doi.org/10.5586/asbp.2002.040

143. Kącki Z, Dajdok Z, Szczęśniak E. Czerwona lista roślin naczyniowych Dolnego Śląska. In: Kącki Z, editor. Zagrożone gatunki flory naczyniowej Dolnego Śląska. Wrocław: Instytut Biologii Roślin, Uniwersytet Wrocławski, Polskie Towarzystwo Przyjaciół Przyrody "Pro Natura"; 2003. p. 9-65.

144. Rutkowski L. Rośliny naczyniowe - Tracheophyta. In: Buszko J, Kasprzyk K, Pawlikowski T, Przystański A, Rutkowski L, editors. Czerwona lista roślin i zwierząt ginących i zagrożonych w regionie kujawsko-pomorskim. Acta Univ Nicolai Copernici. Biologia LIII, Suplement-Nauki Mat-Przyr Toruń. 1997;98:5-20.

145. Bróż E, Przemyski A. The red list of vascular plants in the Wyżyna Małopolska upland (S Poland). In: Mirek Z, Nikel A, editors. Rare, relict and endangered plants and fungi in Poland. Kraków: W. Szafer Intitute of Botany, Polish Academy of Sciences; 2009.

146. Korneck D, Schnittler M, Vollmer I. Rote liste der Farn- und Blütenpflanzen (Pteridophyta \& Spermatophyta) Deutschlands. Schrift Vegetationsk. 1996;28:21-187.

147. Ludwig G, May R, Otto C. Verantwortlichkeit Deutschlands für die weltweite Erhaltung der Farn- und Blütenpflanzen - vorläufige Liste. BfN-Skripten 220; 2007.

148. Procházka F, editor. Červený a černý seznam cévnatých rostlin České republiky (stav v roce 2000). Praha: Příroda; 2001.

149. Feráková V, Maglocky Š, Marhold K. Červený zoznam paprad’orastov a semenných rastlín Slovenska. In: Baláz D, Marhold K, Urban P, editors. Cerveny zoznam rastlín a zivocíchov Slovenska. Ochr Prír. 2001;20:44-76.

150. Parusel JB, Urbisz A, editors. Czerwona lista roślin naczyniowych województwa śląskiego. Raporty, Opinie. Katowice: CDPGŚ; 2012. (vol 6). 